\title{
Stereoselective Synthesis of 3-Alkylideneoxindoles via Palladium-Catalyzed Domino Reactions
}

Reiko Yanada, Shingo Obika, Tsubasa Inokuma, Kazuo Yanada, Masayuki Yamashita, Shunsaku Ohta, Yoshiji Takemoto*

Graduate School of Pharmaceutical Sciences, Kyoto University, Yoshida, Sakyo-ku, Kyoto 606-8501, Japan

Kyoto Pharmaceutical University, Misasagi-Nakauchicho 5, Yamashinaku, Kyoto 607-8414, Japan

\section{Supporting Information}

General$-\mathrm{S} 2$

Spectroscopic data:

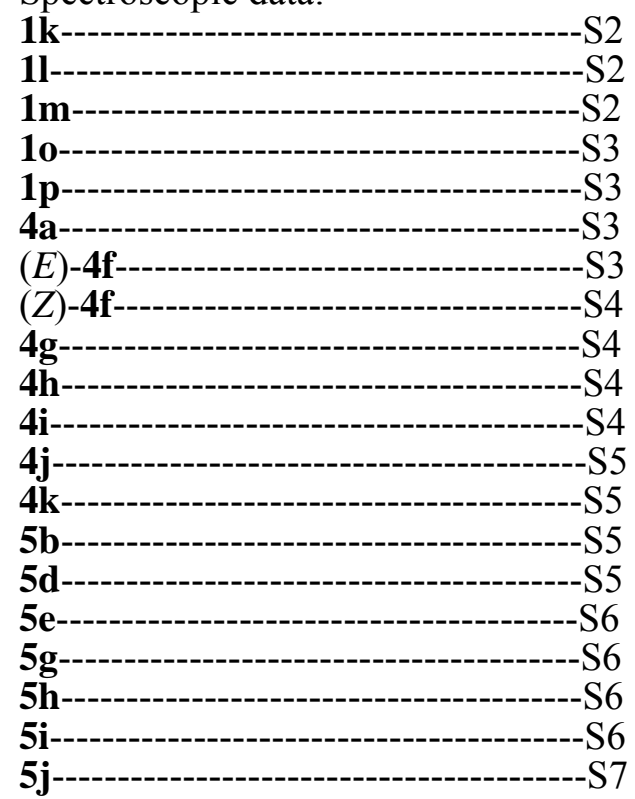

Table of Contents:

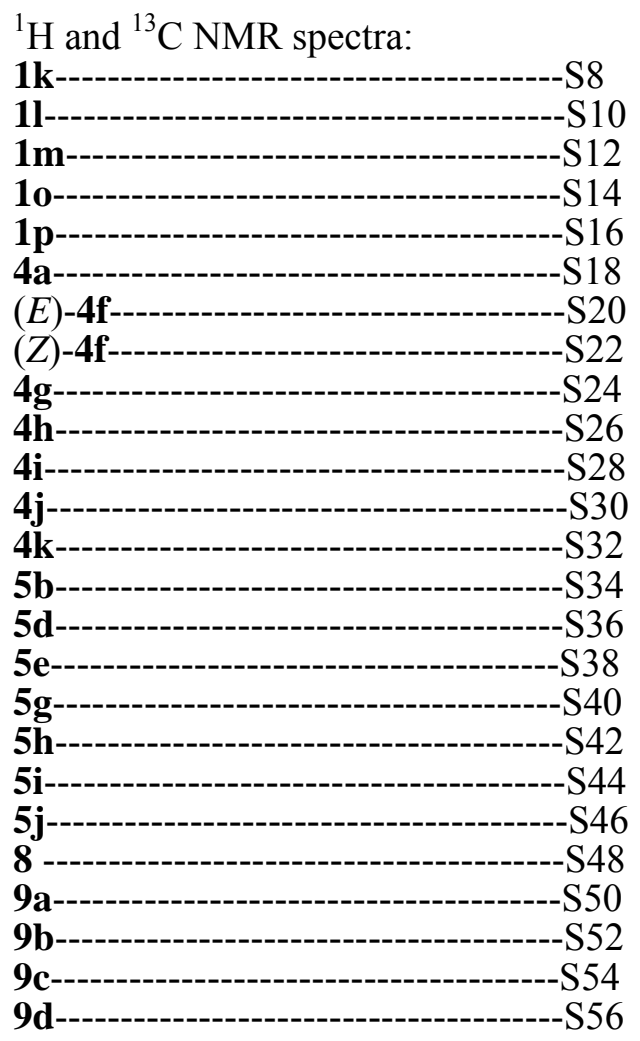


General. ${ }^{1} \mathrm{H}$ NMR and ${ }^{13} \mathrm{C}$ NMR spectra were registered on $500 \mathrm{MHz}$ NMR using TMS as an internal standard. $(\mathrm{s}=$ singlet, $\mathrm{d}=$ doublet, $\mathrm{dd}=$ double doublet, $\mathrm{ddd}=$ doublet of double doublets, $\mathrm{t}$ $=$ triplet, $\mathrm{q}=$ quartet, $\mathrm{m}=$ multiplet, $\mathrm{br}=$ broad). For column chromatography, Silica gel 60 (spherical, 63-210 $\mu \mathrm{m}$ ) was employed and preparative thin-layer chromatography (PTLC) was carried out using Silica gel $60 \mathrm{~F}_{254}$. All reactions were carried out under a positive pressure of argon or nitrogen.

\section{N-(2-Iodophenyl)-3-phenylpropiolamide (1k)}

${ }^{1} \mathrm{H}$ NMR $\left(500 \mathrm{MHz}, \mathrm{CDCl}_{3}\right) \delta 7.87(\mathrm{~d}, J=7.9 \mathrm{~Hz}, 1 \mathrm{H}), 7.66-7.64(\mathrm{~m}, 2 \mathrm{H}), 7.51-7.49(\mathrm{~m}, 1 \mathrm{H})$, 7.43-7.39 (m, 3H), $7.20(\mathrm{~d}, J=7.9 \mathrm{~Hz}, 1 \mathrm{H}), 7.02(\mathrm{t}, J=7.9 \mathrm{~Hz}, 1 \mathrm{H}) ;{ }^{13} \mathrm{C} \mathrm{NMR}\left(126 \mathrm{MHz}, \mathrm{CDCl}_{3}\right) \delta$ $150.9,138.9,137.8,132.7,130.4,129.3,128.5,126.0,122.4,119.7,89.6,86.4,83.2 ; \mathrm{IR}\left(\mathrm{CHCl}_{3}\right) \vee$ 3008, $1633 \mathrm{~cm}^{-1}$; MS (FAB) m/z $348\left(\mathrm{MH}^{+}\right)$; HRMS (FAB) calcd for $\mathrm{C}_{15} \mathrm{H}_{11} \mathrm{INO}\left(\mathrm{MH}^{+}\right) 347.9887$, found 347.9885 .

\section{$N$-(2-Iodophenyl)-3-(thiophen-3-yl)propiolamide (11)}

${ }^{1} \mathrm{H}$ NMR (500 MHz, $\left.\mathrm{CDCl}_{3}\right) \delta 8.23(\mathrm{~d}, J=8.0 \mathrm{~Hz}, 1 \mathrm{H}), 7.81-7.77(\mathrm{~m}, 3 \mathrm{H}), 7.38-7.35(\mathrm{~m}, 2 \mathrm{H}), 6.88$ $(\mathrm{t}, J=7.0 \mathrm{~Hz}, 1 \mathrm{H}) ;{ }^{13} \mathrm{C} \mathrm{NMR}\left(126 \mathrm{MHz}, \mathrm{CDCl}_{3}\right) \delta 151.0,139.0,137.8,133.2,130.1,129.4,126.6$, 126.2, 119.0, 89.5, 83.1, 82.0; IR $\left(\mathrm{CHCl}_{3}\right) \vee 2960,1631 \mathrm{~cm}^{-1}$; Anal. Calcd for $\mathrm{C}_{13} \mathrm{H}_{8} \mathrm{INOS}$ : C, 44.21; H, 2.28; I, 35.93; N, 3.97; O, 4.53. Found: C, 44.09; H, 2.51; I, 35.71; N, 3.82; O, 4.35.

\section{N-(2-Iodophenyl)pent-2ynamide (1m)}

${ }^{1} \mathrm{H}$ NMR $\left(500 \mathrm{MHz}, \mathrm{CDCl}_{3}\right) \delta 8.21(\mathrm{~d}, J=8.5 \mathrm{~Hz}, 1 \mathrm{H}), 7.80(\mathrm{~d}, J=8.0 \mathrm{~Hz}, 1 \mathrm{H}), 7.65(\mathrm{br}, 1 \mathrm{H}), 7.34$ $(\mathrm{t}, J=8.0 \mathrm{~Hz}, 1 \mathrm{H}), 6.86(\mathrm{~m}, 1 \mathrm{H}), 2.42(\mathrm{~d}, J=7.9 \mathrm{~Hz}, 2 \mathrm{H}), 1.26(\mathrm{t}, J=7.9 \mathrm{~Hz}, 3 \mathrm{H}) ;{ }^{13} \mathrm{C} \mathrm{NMR}(126$ $\left.\mathrm{MHz}, \mathrm{CDCl}_{3}\right) \delta 151.1,138.9,137.9,129.3,126.3,122.3,90.5,89.3,75.2,12.6,12.4 ; \mathrm{IR}\left(\mathrm{CHCl}_{3}\right) \vee$ 3010, $1635 \mathrm{~cm}^{-1}$; Anal. Calcd for $\mathrm{C}_{11} \mathrm{H}_{10} \mathrm{INO}$ : C, 44.17; H, 3.37; N, 4.68; O, 5.35. Found: C, 43.90; $\mathrm{H}, 3.21 ; \mathrm{N}, 4.68 ; \mathrm{O}, 5.23$.

\section{2-Iodophenyl 3-phenylpropiolate (10)}

${ }^{1} \mathrm{H}$ NMR $\left(500 \mathrm{MHz}, \mathrm{CDCl}_{3}\right) \delta 7.87(\mathrm{~d}, J=8.0 \mathrm{~Hz}, 1 \mathrm{H}), 7.65(\mathrm{~d}, J=8.6 \mathrm{~Hz}, 2 \mathrm{H}), 7.51-7.49(\mathrm{~m}, 1 \mathrm{H})$, 
7.43-7.38 (m, 3H), 7.19 (d, $J=8.0 \mathrm{~Hz}, 1 \mathrm{H}), 7.02(\mathrm{t}, J=6.1 \mathrm{~Hz}, 1 \mathrm{H}) ;{ }^{13} \mathrm{C} \mathrm{NMR}\left(126 \mathrm{MHz}, \mathrm{CDCl}_{3}\right)$ $\delta 151.5,150.8,139.8,133.4,131.2,129.6,128.7,128.2,123.0,119.2,90.1,89.4,80.2 ; \mathrm{IR}\left(\mathrm{CHCl}_{3}\right)$ v 3001, $1632 \mathrm{~cm}^{-1}$; Anal. Calcd for $\mathrm{C}_{15} \mathrm{H}_{9} \mathrm{IO}_{2}:$ C, 51.90; H, 2.90; N, 4.03; I, 36.56. Found: C, 52.05; H, 3.09; N, 3.99; I, 36.32.

\section{2-Iodophenyl hept-2-ynoate (1p)}

${ }^{1} \mathrm{H}$ NMR $\left(500 \mathrm{MHz}, \mathrm{CDCl}_{3}\right) \delta 7.84(\mathrm{~d}, J=8.0 \mathrm{~Hz}, 1 \mathrm{H}), 7.37(\mathrm{t}, J=7.9 \mathrm{~Hz}, 1 \mathrm{H}), 7.12(\mathrm{~d}, J=8.0 \mathrm{~Hz}$, $1 \mathrm{H}), 6.99(\mathrm{t}, J=7.9 \mathrm{~Hz}, 1 \mathrm{H}), 2.41(\mathrm{t}, J=7.0 \mathrm{~Hz}, 2 \mathrm{H}), 1.64-1.56(\mathrm{~m}, 2 \mathrm{H}), 1.48-1.44(\mathrm{~m}, 2 \mathrm{H}), 0.94$ $(\mathrm{t}, J=7.3 \mathrm{~Hz}, 3 \mathrm{H}) ;{ }^{13} \mathrm{C}$ NMR $\left(126 \mathrm{MHz}, \mathrm{CDCl}_{3}\right) \delta 151.1,150.6,139.6,129.5,128.0,122.9,93.1$, 90.1, 72.5, 29.3, 21.8, 18.4, 13.4; IR $\left(\mathrm{CHCl}_{3}\right) \vee 3010,1636 \mathrm{~cm}^{-1} ; \mathrm{MS}(\mathrm{FAB}) \mathrm{m} / \mathrm{z} 329\left(\mathrm{MH}^{+}\right)$; HRMS (FAB) calcd for $\mathrm{C}_{13} \mathrm{H}_{14} \mathrm{IO}_{2}\left(\mathrm{MH}^{+}\right) 329.0044$, found 329.0046 .

\section{1-Benzyl-3-(diphenylmethylene)indolin-2-one (4a)}

${ }^{1} \mathrm{H}$ NMR $\left(500 \mathrm{MHz}, \mathrm{CDCl}_{3}\right) \delta 7.67(\mathrm{~m}, 1 \mathrm{H}), 7.43-7.24(\mathrm{~m}, 14 \mathrm{H}), 7.04(\mathrm{t}, J=7.6 \mathrm{~Hz}, 1 \mathrm{H})$, 6.67-6.62 (m, 2H), $6.41(\mathrm{~d}, J=7.7 \mathrm{~Hz}, 1 \mathrm{H}), 4.92(\mathrm{~s}, 2 \mathrm{H}) ;{ }^{13} \mathrm{C} \mathrm{NMR}\left(126 \mathrm{MHz}, \mathrm{CDCl}_{3}\right) \delta 167.4$, $148.4,143.5,137.5,135.8,130.5,129.6,129.1,128.9,128.2,127.8,127.4,125.2,122.2$, 108.9, 43.5; IR $\left(\mathrm{CHCl}_{3}\right) v^{\sim} \quad . .1 \quad 1 \quad \mathrm{~cm}^{-1}$; MS (FAB) m/z $388\left(\mathrm{MH}^{\dagger}\right)$; HRMS (FAB) calcd for $\mathrm{C}_{28} \mathrm{H}_{22} \mathrm{NO}$ $\left(\mathrm{MH}^{+}\right)$388.1701, found 388.1703.

\section{(E)-1-Benzyl-3-(1-phenylpentylidene)indolin-2-one (4f)}

${ }^{1} \mathrm{H}$ NMR (500 MHz, $\left.\mathrm{CDCl}_{3}\right) \delta$ 7.50-7.45 (m, 3H), 7..32-7.23 (m, 7H), 6.99 (t, J=7.7 Hz, 1H), 6.64 $(\mathrm{m}, J=8.0 \mathrm{~Hz}, 1 \mathrm{H}), 6.57(\mathrm{~m}, 1 \mathrm{H}), 6.02(\mathrm{~d}, J=7.9 \mathrm{~Hz}, 1 \mathrm{H}), 4.99(\mathrm{~s}, 2 \mathrm{H}), 3.35-3.33(\mathrm{~m}, 2 \mathrm{H})$, 1.49-1.42 (m, 4H), 0.90 (t, $J=5.2 \mathrm{~Hz}, 3 \mathrm{H}) ;{ }^{13} \mathrm{C}$ NMR (126 MHz, $\left.\mathrm{CDCl}_{3}\right) \delta 167.9,160.3,141.5$, $136.5,129.1,128.7,128.3,128.0,127.4,126.9,123.1,1229 ., 121.4,108.4,43.2,34.9,29.8,22.9$, 13.9; IR $\left(\mathrm{CHCl}_{3}\right) \vee \quad \quad . . \quad . .11^{\sim} \mathrm{cm}^{-1}$; MS (FAB) m/z $368\left(\mathrm{MH}^{+}\right)$; HRMS (FAB) calcd for $\mathrm{C}_{26} \mathrm{H}_{26} \mathrm{NO}\left(\mathrm{MH}^{+}\right)$368.2014, found 368.2017.

\section{(Z)-1-Benzyl-3-(1-phenylpentylidene)indolin-2-one (4f)}

${ }^{1} \mathrm{H}$ NMR $\left(500 \mathrm{MHz}, \mathrm{CDCl}_{3}\right) \delta 7.60(\mathrm{~d}, J=7.6 \mathrm{~Hz}, 1 \mathrm{H}), 7.44-7.38(\mathrm{~m}, 3 \mathrm{H}), 7.32-7.16(\mathrm{~m}, 8 \mathrm{H}), 7.04$ 
(t, $J=7.6 \mathrm{~Hz}, 1 \mathrm{H}), 6.70(\mathrm{~d}, J=7.6 \mathrm{~Hz}, 1 \mathrm{H}), 4.85(\mathrm{~s}, 2 \mathrm{H}), 2.95(\mathrm{t}, J=8.5 \mathrm{~Hz}, 2 \mathrm{H}), 1.63-1.58(\mathrm{~m}$, 2H), $1.50-1.45(\mathrm{~m}, 2 \mathrm{H}), 0.94(\mathrm{t}, J=7.3 \mathrm{~Hz}, 3 \mathrm{H}) ;{ }^{13} \mathrm{C} \mathrm{NMR}\left(126 \mathrm{MHz}, \mathrm{CDCl}_{3}\right) \delta 166.5,158.8$, $142.6,141.7,136.4,128.6,128.4,128.1,128.0,127.5,127.3,123.5,123.0,121.8,108.9,43.2,37.9$,

28.9, 23.0, 13.8; IR $\left(\mathrm{CHCl}_{3}\right)$ y $\quad$.. $\quad . .{ }^{\sim} \quad \mathrm{cm}^{-1}$; MS (FAB) $\mathrm{m} / \mathrm{z} 368\left(\mathrm{MH}^{+}\right)$; HRMS (FAB) calcd for $\mathrm{C}_{26} \mathrm{H}_{26} \mathrm{NO}\left(\mathrm{MH}^{+}\right)$368.2014, found 368.2016.

\section{(Z)-1-Benzyl-3-(2-(benzyloxy)-1-phenylethylidene)indolin-2-one (4g)}

${ }^{1} \mathrm{H}$ NMR (500 MHz, $\left.\mathrm{CDCl}_{3}\right) \delta$ 7.50-7.47 (m, 3H), 7.36-7.23 (m, 12H), $7.04(\mathrm{t}, J=7.6 \mathrm{~Hz}, 1 \mathrm{H})$, 6.66-6.59 (m, 2H), 6.15 (d, J=7.6 Hz, 1H), 5.34 (s, 2H), $4.97(\mathrm{~s}, 2 \mathrm{H}), 4.56(\mathrm{~s}, 2 \mathrm{H}),{ }^{13} \mathrm{C} \mathrm{NMR}(126$ $\left.\mathrm{MHz}, \mathrm{CDCl}_{3}\right) \delta 167.6,154.1,142.3,138.6,138.4,136.2,128.9,128.8,128.5,128.2,127.7,127.6$, $127.5,127.3,125.0,123.6,122.3,121.7,108.6,72.8,68.5,43.4 ; \mathrm{IR}\left(\mathrm{CHCl}_{3}\right) \vee 2961,1650 \mathrm{~cm}^{-1} ; \mathrm{MS}$ (FAB) m/z $432\left(\mathrm{MH}^{+}\right)$; HRMS (FAB) calcd for $\mathrm{C}_{30} \mathrm{H}_{26} \mathrm{NO}_{2}\left(\mathrm{MH}^{+}\right)$432.1963, found 432.1965.

\section{(Z)-1-Benzyl-3-(2-(benzyloxy)-1-(4-methoxyphenyl)ethylidene)indolin-2-one (4h)}

${ }^{1} \mathrm{H}$ NMR $\left(500 \mathrm{MHz}, \mathrm{CDCl}_{3}\right) \delta$ 7.32-7.16 (m, 12H), 7.04-6.99 (m, 3H), 6.66-6.63 (m, 2H), $6.36(\mathrm{~d}$, $J=7.7 \mathrm{~Hz}, 1 \mathrm{H}), 5.32(\mathrm{~s}, 2 \mathrm{H}), 4.97(\mathrm{~s}, 2 \mathrm{H}), 4.55(\mathrm{~s}, 2 \mathrm{H}), 3.89(\mathrm{~s}, 3 \mathrm{H}) ;{ }^{13} \mathrm{C} \mathrm{NMR}\left(126 \mathrm{MHz}, \mathrm{CDCl}_{3}\right)$ $\delta 167.6,160.0,154.2,142.2,130.7,129.4,128.8,128.2,127.8,127.5,127.4,127.3,123.5,121.6$, 114.3, 108.6, 72.7, 68.5, 55.3, 43.4; IR $\left(\mathrm{CHCl}_{3}\right) \vee 2960,1648 \mathrm{~cm}^{-1} ; \mathrm{MS}(\mathrm{FAB}) \mathrm{m} / \mathrm{z} 462\left(\mathrm{MH}^{+}\right)$; HRMS (FAB) calcd for $\mathrm{C}_{31} \mathrm{H}_{28} \mathrm{NO}_{3}\left(\mathrm{MH}^{+}\right)$462.2069, found 462.2065.

\section{(E)-1-Benzyl-5-methyl-3-(1-phenylpentylidene)-indolin-2-one (4i)}

${ }^{1} \mathrm{H}$ NMR (500 MHz, $\left.\mathrm{CDCl}_{3}\right)$ $\delta$ 7.50-7.45 (m, 3H), 7.32-7.29 (m, 4H), 7.27-7.22 (m, 3H), $6.80(\mathrm{~d}, J$ $=8.0 \mathrm{~Hz}, 1 \mathrm{H}), 6.51(\mathrm{~d}, J=8.0 \mathrm{~Hz}, 1 \mathrm{H}), 5.77(\mathrm{~s}, 1 \mathrm{H}), 4.97(\mathrm{~s}, 2 \mathrm{H}), 3.36(\mathrm{t}, J=7.3 \mathrm{~Hz}, 2 \mathrm{H}), 1.94(\mathrm{~s}$, $3 \mathrm{H}), 1.52-1.41(\mathrm{~m}, 4 \mathrm{H}), 0.91(\mathrm{t}, J=6.7 \mathrm{~Hz}, 3 \mathrm{H}) ;{ }^{13} \mathrm{C} \mathrm{NMR}\left(126 \mathrm{MHz}, \mathrm{CDCl}_{3}\right) \delta 167.8,159.9$, $141.8,139.3,136.6,130.5,129.0,128.7,128.3,128.2,127.4,127.3,127.0,123.9,123.3,122.9$, 108.1, 43.2, 34.8, 29.8, 22.9, 21.0, 13.9; IR $\left(\mathrm{CHCl}_{3}\right) \vee 3009,2686 \mathrm{~cm}^{-1}$; MS (FAB) m/z $382\left(\mathrm{MH}^{+}\right)$; HRMS (FAB) calcd for $\mathrm{C}_{27} \mathrm{H}_{28} \mathrm{NO}\left(\mathrm{MH}^{+}\right)$382.2170, found 382.2152.

\section{(E)-1-Benzyl-2-oxo-3-(1-phenylpentylidene)-indoline-5-carbonitrile (4j)}

${ }^{1} \mathrm{H}$ NMR $\left(500 \mathrm{MHz}, \mathrm{CDCl}_{3}\right) \delta$ 7.55-7.52 (m, 3H), 7.36-7.23 (m, 8H), $6.70(\mathrm{~d}, J=8.0 \mathrm{~Hz}, 1 \mathrm{H}), 6.22$ 
$(\mathrm{s}, 1 \mathrm{H}), 5.01(\mathrm{~s}, 2 \mathrm{H}), 3.37(\mathrm{t}, J=7.3 \mathrm{~Hz}, 2 \mathrm{H}), 1.53-1.42(\mathrm{~m}, 4 \mathrm{H}), 0.91(\mathrm{t}, J=7.0 \mathrm{~Hz}, 3 \mathrm{H}) ;{ }^{13} \mathrm{C} \mathrm{NMR}$ $\left(126 \mathrm{MHz}, \mathrm{CDCl}_{3}\right) \delta 167.4,164.4,144.6,140.6,135.4,132.6,129.5,129.2,128.9,127.9,127.2$, $126.4,126.2,123.5,121.3,119.4,108.8,104.5,43.4,35.2,29.7,22.9,13.8 ;$ IR $\left(\mathrm{CHCl}_{3}\right)$ $\tilde{y}^{\sim}{ }_{1} . .1 \quad . \mathrm{cm}^{-1}$; MS (FAB) $\mathrm{m} / \mathrm{z} 393\left(\mathrm{MH}^{+}\right)$; HRMS (FAB) calcd for $\mathrm{C}_{27} \mathrm{H}_{25} \mathrm{~N}_{2} \mathrm{O}\left(\mathrm{MH}^{+}\right)$392.1889, found 392.1890 .

\section{(E)-1-Benzyl-5-(trifluoromethyl)-3-(1-phenylpentylidene)-indolin-2-one (4k)}

${ }^{1} \mathrm{H}$ NMR (500 MHz, $\left.\mathrm{CDCl}_{3}\right) \delta$ 7.53-7.49 (m, 3H), 7.36-7.25 (m, 8H), 6.69 (d, J = 8.0 Hz, 1H), 6.17 $(\mathrm{s}, 1 \mathrm{H}), 5.02(\mathrm{~s}, 2 \mathrm{H}), 3.38(\mathrm{t}, J=7.9 \mathrm{~Hz}, 2 \mathrm{H}), 1.55-1.43(\mathrm{~m}, 4 \mathrm{H}), 0.92(\mathrm{t}, J=7.3 \mathrm{~Hz}, 3 \mathrm{H}) ;{ }^{13} \mathrm{C} \mathrm{NMR}$ $\left(126 \mathrm{MHz}, \mathrm{CDCl}_{3}\right) \delta 163.1,155.3,140.9,138.9,135.8,131.9,129.3,128.9,128.8,127.7,127.3$, 126.6, 125.2, 123.0, 120.0, 117.4, 109.1, 108.1, 43.4, 34.9, 29.7, 22.9, 13.9; IR $\left(\mathrm{CHCl}_{3}\right)$ v 2931, $1697 \mathrm{~cm}^{-1}$; MS (FAB) m/z $436\left(\mathrm{MH}^{+}\right)$; HRMS (FAB) calcd for $\mathrm{C}_{27} \mathrm{H}_{25} \mathrm{~F}_{3} \mathrm{NO}\left(\mathrm{MH}^{+}\right)$436.1888, found 436.1885 .

\section{(E)-((4-Methoxyphenyl)(phenyl)methylene)indolin-2-one (5b)}

${ }^{1} \mathrm{H}$ NMR $\left(500 \mathrm{MHz}, \mathrm{CDCl}_{3}\right) \delta 7.87$ (br, 1H), 7.38-7.25 (m, 7H), $7.10(\mathrm{~m}, 1 \mathrm{H}), 6.94(\mathrm{~d}, J=8.9 \mathrm{~Hz}$, 2H), 6.76-6.62 (m, 3H), $3.87(\mathrm{~s}, 3 \mathrm{H}) ;{ }^{13} \mathrm{C} \mathrm{NMR}\left(126 \mathrm{MHz}, \mathrm{CDCl}_{3}\right) \delta 168.5,160.9,155.4,140.4$, 133.6, 131.8, 130.7, 129.4, 128.6, 127.8, 124.6, 123.1, 121.3, 114.3, 109.4, 55.4; IR $\left(\mathrm{CHCl}_{3}\right) \vee 2961$, $1643 \mathrm{~cm}^{-1}$; MS (FAB) m/z $328\left(\mathrm{MH}^{+}\right)$; HRMS (FAB) calcd for $\mathrm{C}_{22} \mathrm{H}_{18} \mathrm{NO}_{2}\left(\mathrm{MH}^{+}\right)$328.1337, found 328.1335 .

\section{(Z)-(Phenyl(thiophen-3-yl)methylene)indolin-2-one (5d)}

${ }^{1} \mathrm{H}$ NMR (500 MHz, $\left.\mathrm{CDCl}_{3}\right) \delta 8.47$ (br, 1H), 7.46-7.24 (m, 6H), 7.09-7.05 (m, 3H), 6.75-6.70 (m, $3 \mathrm{H}) ;{ }^{13} \mathrm{C} \mathrm{NMR}\left(126 \mathrm{MHz}, \mathrm{CDCl}_{3}\right) \delta 167.7,148.1,141.9,140.6,139.8,130.4,129.4,129.0,128.9$, 128.8, 127.8, 127.6, 126.2, 124.1, 122.9, 121.3, 109.7; IR $\left(\mathrm{CHCl}_{3}\right) \vee 2980,1640 \mathrm{~cm}^{-1}$; MS (FAB) m/z $304\left(\mathrm{MH}^{+}\right)$; HRMS (FAB) calcd for $\mathrm{C}_{19} \mathrm{H}_{14} \mathrm{NOS}\left(\mathrm{MH}^{+}\right)$304.0796, found 304.0798.

\section{(E)-3-(1-Phenylpropylidene)indolin-2-one (5e)}

${ }^{1} \mathrm{H}$ NMR $\left(500 \mathrm{MHz}, \mathrm{CDCl}_{3}\right) \delta 8.70(\mathrm{br}, 1 \mathrm{H}), 7.50-7.43(\mathrm{~m}, 3 \mathrm{H}), 7.26(\mathrm{~d}, J=7.6 \mathrm{~Hz}, 2 \mathrm{H}), 7.05$ (br, 
1H), 6.80 (br, 1H), $6.58(\mathrm{t}, J=7.6 \mathrm{~Hz}, 1 \mathrm{H}), 6.00(\mathrm{~d}, J=7.6 \mathrm{~Hz}, 1 \mathrm{H}), 3.35-3.33(\mathrm{~m}, 2 \mathrm{H}), 1.11(\mathrm{t}, J=$ 7.6 Hz, 3H); ${ }^{13} \mathrm{C}$ NMR $\left(126 \mathrm{MHz}, \mathrm{CDCl}_{3}\right) \delta 169.8,161.4,141.3,139.8,129.1,128.3,128.1,126.9$, 123.6, 123.3, 123.2, 121.3, 109.3, 28.0, 11.9; IR $\left(\mathrm{CHCl}_{3}\right) \vee 3001,1640 \mathrm{~cm}^{-1}$; MS (FAB) m/z 250 $\left(\mathrm{MH}^{+}\right)$; HRMS (FAB) calcd for $\mathrm{C}_{17} \mathrm{H}_{16} \mathrm{NO}\left(\mathrm{MH}^{+}\right)$250.1232, found 250.1235.

\section{(E)-3-(Phenyl(p-tolyl)methylene)benzofuran-2(3H)-one (5g)}

${ }^{1} \mathrm{H}$ NMR $\left(500 \mathrm{MHz}, \mathrm{CDCl}_{3}\right) \delta 7.65(\mathrm{~d}, J=6.7 \mathrm{~Hz}, 1 \mathrm{H}), 7.43-7.19(\mathrm{~m}, 8 \mathrm{H}), 7.06-7.04(\mathrm{~m}, 2 \mathrm{H})$, 6.84-6.81 (m, 1H), $6.64(\mathrm{~d}, J=7.9 \mathrm{~Hz}, 1 \mathrm{H}), 2.43(\mathrm{~s}, 3 \mathrm{H}) ;{ }^{13} \mathrm{C} \mathrm{NMR}\left(126 \mathrm{MHz}, \mathrm{CDCl}_{3}\right) \delta 167.1$, $159.8,153.4,140.5,139.7,139.2,133.4,131.2,130.4,130.0,129.7,129.6,129.1,128.7,128.2$, 123.1, 122.8, 110.6, 21.5; IR $\left(\mathrm{CHCl}_{3}\right) \vee 2987,1645 \mathrm{~cm}^{-1}$; MS (FAB) m/z $313\left(\mathrm{MH}^{+}\right)$; HRMS (FAB) calcd for $\mathrm{C}_{22} \mathrm{H}_{17} \mathrm{O}_{2}\left(\mathrm{MH}^{+}\right)$313.1228, found313.1224.

\section{(E)-3-((4-Methoxyphenyl)(phenyl)methylene)benzofuran-2(3H)-one (5h)}

${ }^{1} \mathrm{H}$ NMR $\left(500 \mathrm{MHz}, \mathrm{CDCl}_{3}\right) \delta$ 7.47-7.20 (m, 8H), $7.07(\mathrm{~d}, J=7.9 \mathrm{~Hz}, 1 \mathrm{H}), 6.96(\mathrm{~d}, J=8.9 \mathrm{~Hz}, 2 \mathrm{H})$, 6.89-6.85 (m, 1H), 6.78-6.76 (m, 1H), $3.89(\mathrm{~s}, 3 \mathrm{H}) ;{ }^{13} \mathrm{C}$ NMR (126 MHz, $\left.\mathrm{CDCl}_{3}\right) \delta 161.4,158.9$, $153.4,139.4,132.5,131.8,130.7,130.1,129.7,129.4,129.0,128.0,124.9,123.0,122.4,114.3$, 110.6, 55.4; IR $\left(\mathrm{CHCl}_{3}\right) \vee$ 3001. $1608 \mathrm{~cm}^{-1}$; MS (FAB) m/z $329\left(\mathrm{MH}^{+}\right)$; HRMS (FAB) calcd for $\mathrm{C}_{22} \mathrm{H}_{17} \mathrm{O}_{3}\left(\mathrm{MH}^{+}\right)$329.1178, found 329.1179.

\section{(E)-3-((4-(Trifuluoromethyl)phenyl)(phenyl)methylene)benzofuran-2(3H)-one (5i)}

${ }^{1} \mathrm{H}$ NMR $\left(500 \mathrm{MHz}, \mathrm{CDCl}_{3}\right) \delta 7.63(\mathrm{~d}, J=7.9 \mathrm{~Hz}, 2 \mathrm{H}), 7.51-7.38(\mathrm{~m}, 5 \mathrm{H}), 7.32-7.26(\mathrm{~m}, 4 \mathrm{H}), 7.08$ $(\mathrm{d}, J=8.0 \mathrm{~Hz}, 1 \mathrm{H}), 6.86-6.84(\mathrm{~m}, 1 \mathrm{H}) ;{ }^{13} \mathrm{C} \mathrm{NMR}\left(126 \mathrm{MHz}, \mathrm{CDCl}_{3}\right) \delta 167.4,154.9,142.6,140.6$, $132.7,130.4,129.7,129.3,129.1,128.3,123.4,114.9,110.9 ; \mathrm{IR}\left(\mathrm{CHCl}_{3}\right) \vee 2977,1610 \mathrm{~cm}^{-1} \mathrm{MS}$ (FAB) m/z $367\left(\mathrm{MH}^{+}\right)$; HRMS (FAB) calcd for $\mathrm{C}_{22} \mathrm{H}_{14} \mathrm{~F}_{3} \mathrm{O}_{2}\left(\mathrm{MH}^{+}\right)$367.0946, found 367.0948.

\section{(E)-3-(1-Phenylpentylidene)benzofuran-2(3H)-one (5j)}

${ }^{1} \mathrm{H}$ NMR (500 MHz, $\left.\mathrm{CDCl}_{3}\right) \delta$ 7.52-7.44 (m, 3H), 7.27-7.26 (m, 2H), 7.16 (t, J=8.0 Hz, 1H), 7.02 
$(\mathrm{d}, J=7.9 \mathrm{~Hz}, 1 \mathrm{H}), 6.73(\mathrm{t}, J=7.9 \mathrm{~Hz}, 1 \mathrm{H}), 6.11(\mathrm{~d}, J=7.9 \mathrm{~Hz}, 1 \mathrm{H}), 3.23$ (t, $J=7.0 \mathrm{~Hz}, 2 \mathrm{H})$, 1.47-1.41 (m, 4H), $0.92(\mathrm{~m}, 3 \mathrm{H}) ;{ }^{13} \mathrm{C}$ NMR (126 MHz, $\left.\mathrm{CDCl}_{3}\right) \delta 167.2,163.6,152.8,140.6,129.3$, $128.9,126.6,123.7,123.3,122.8,119.0,110.4,35.1,29.7,22.7,13.8 ; \mathrm{IR}\left(\mathrm{CHCl}_{3}\right) \vee 2980,1620$ $\mathrm{cm}^{-1}$; MS (FAB) m/z $279\left(\mathrm{MH}^{+}\right)$; HRMS (FAB) calcd for $\mathrm{C}_{19} \mathrm{H}_{19} \mathrm{O}_{2}\left(\mathrm{MH}^{+}\right)$279.1384, found 279.1385 . 


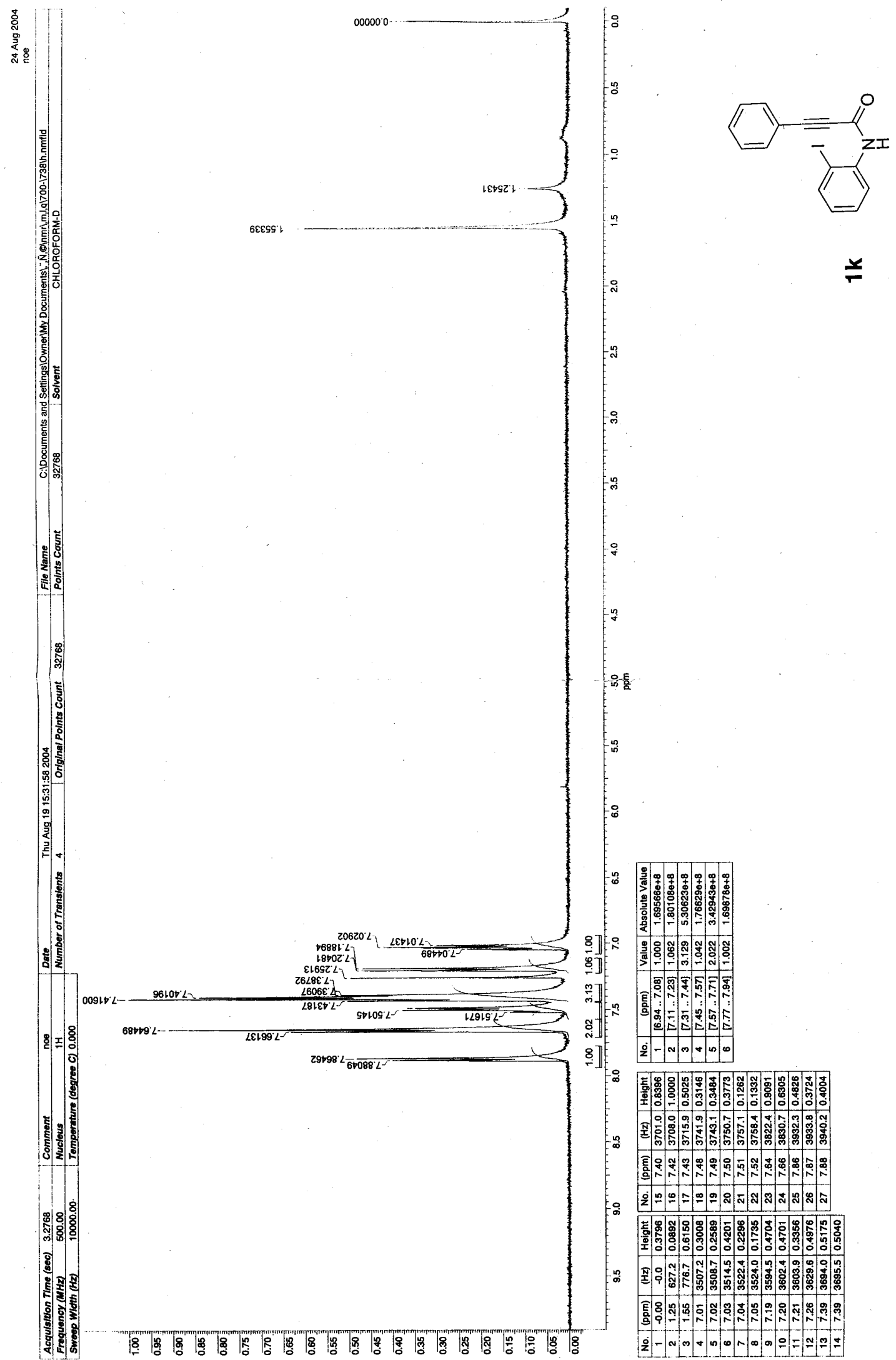




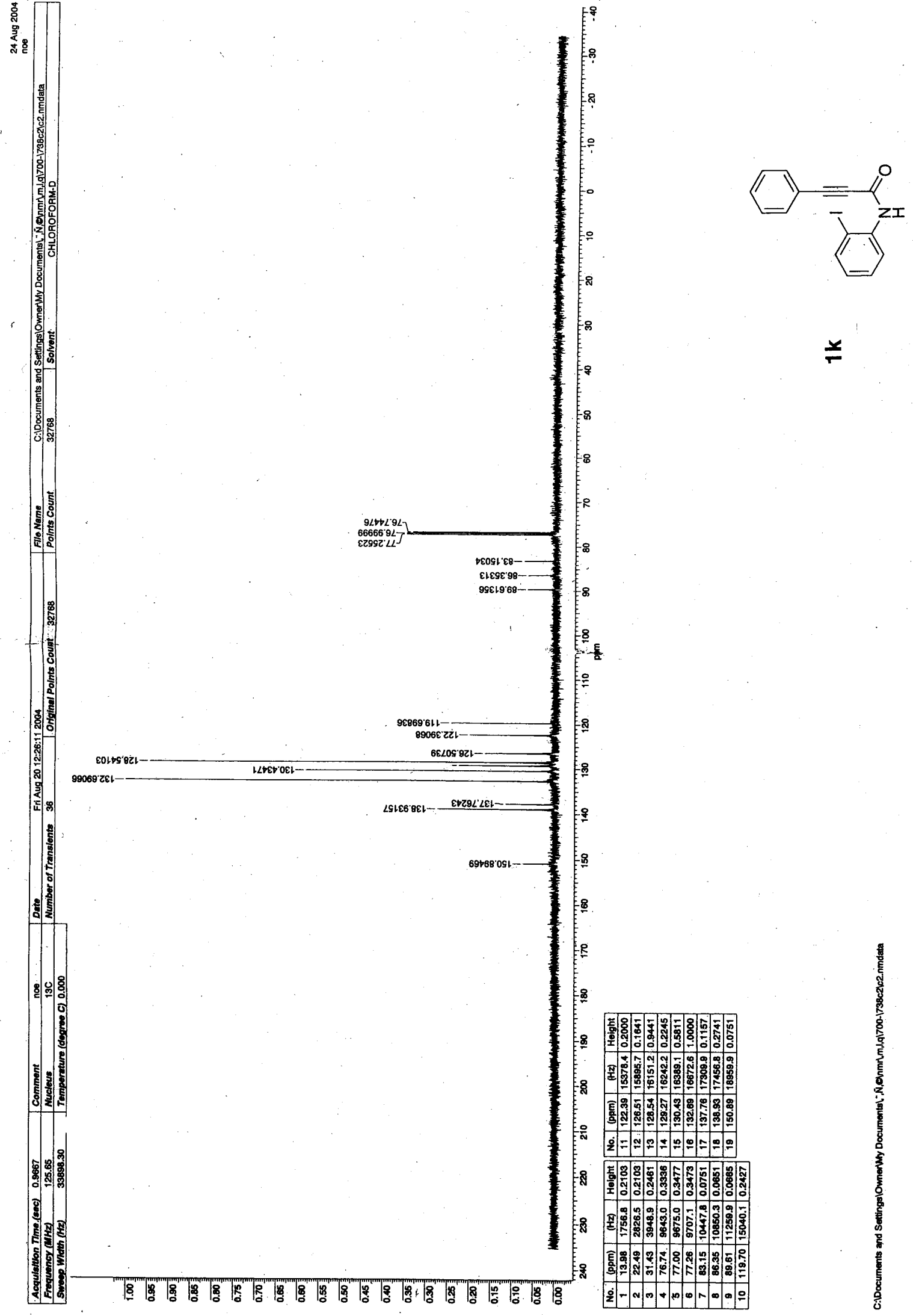




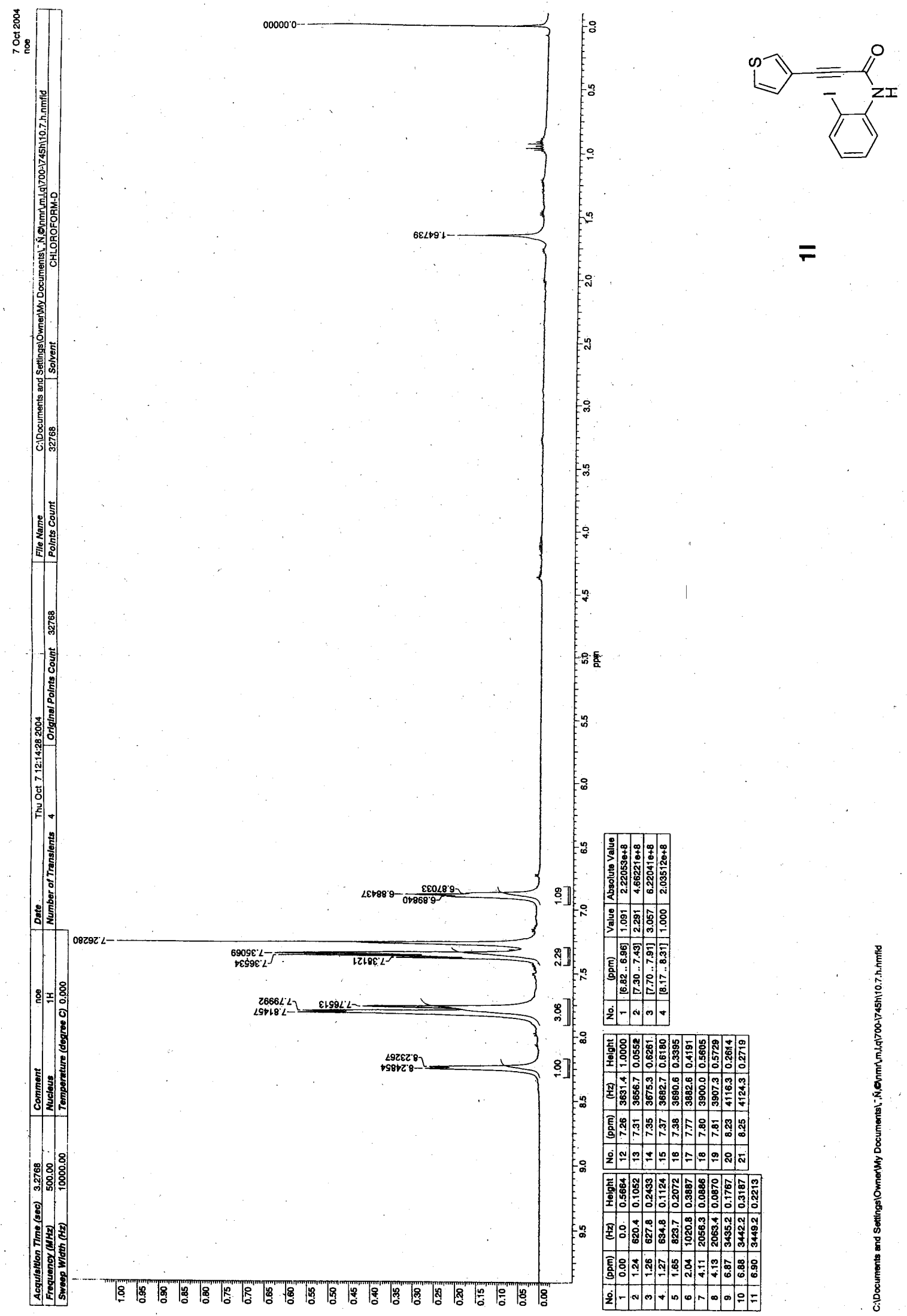




$$
\mathrm{H}
$$




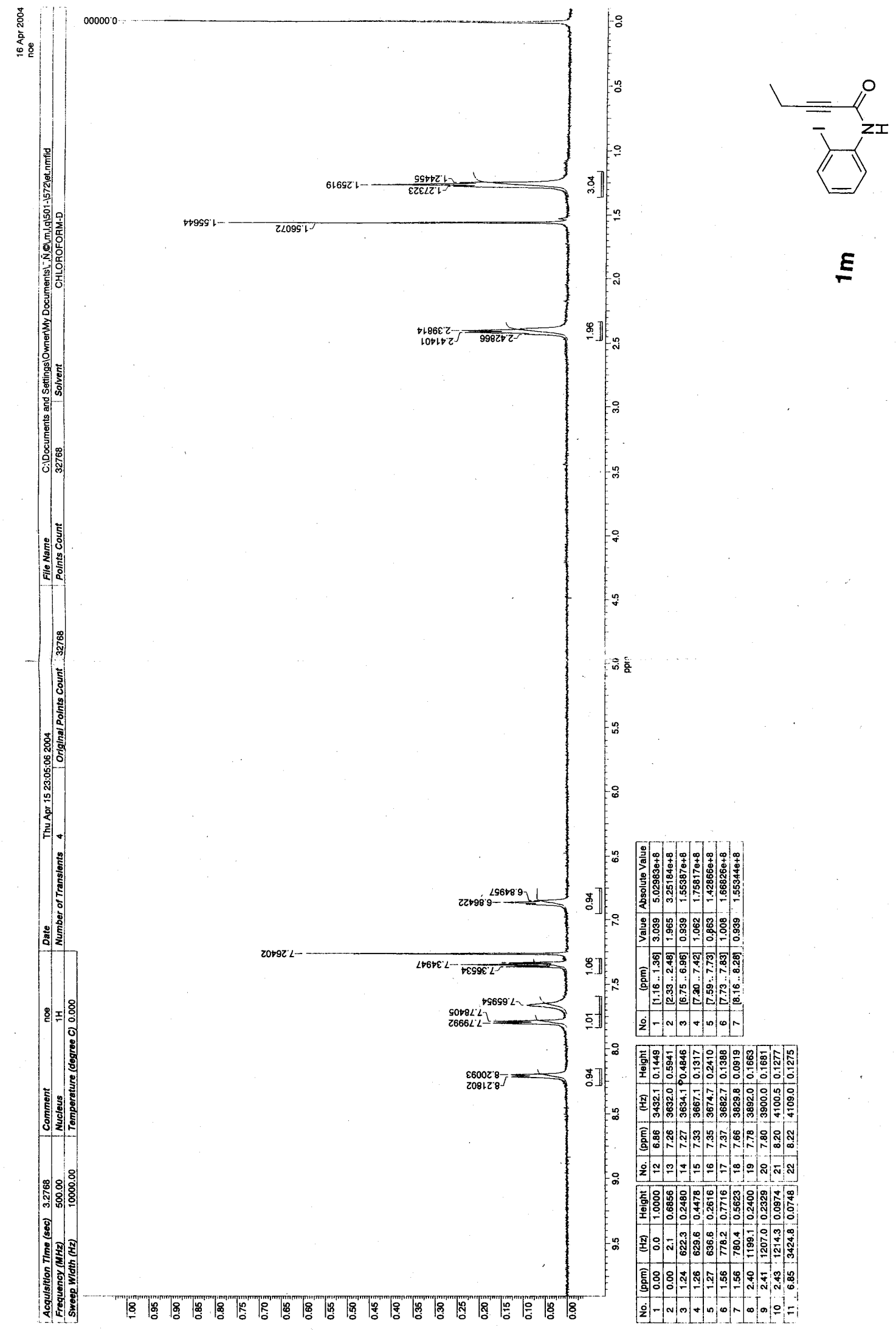




$$
H
$$




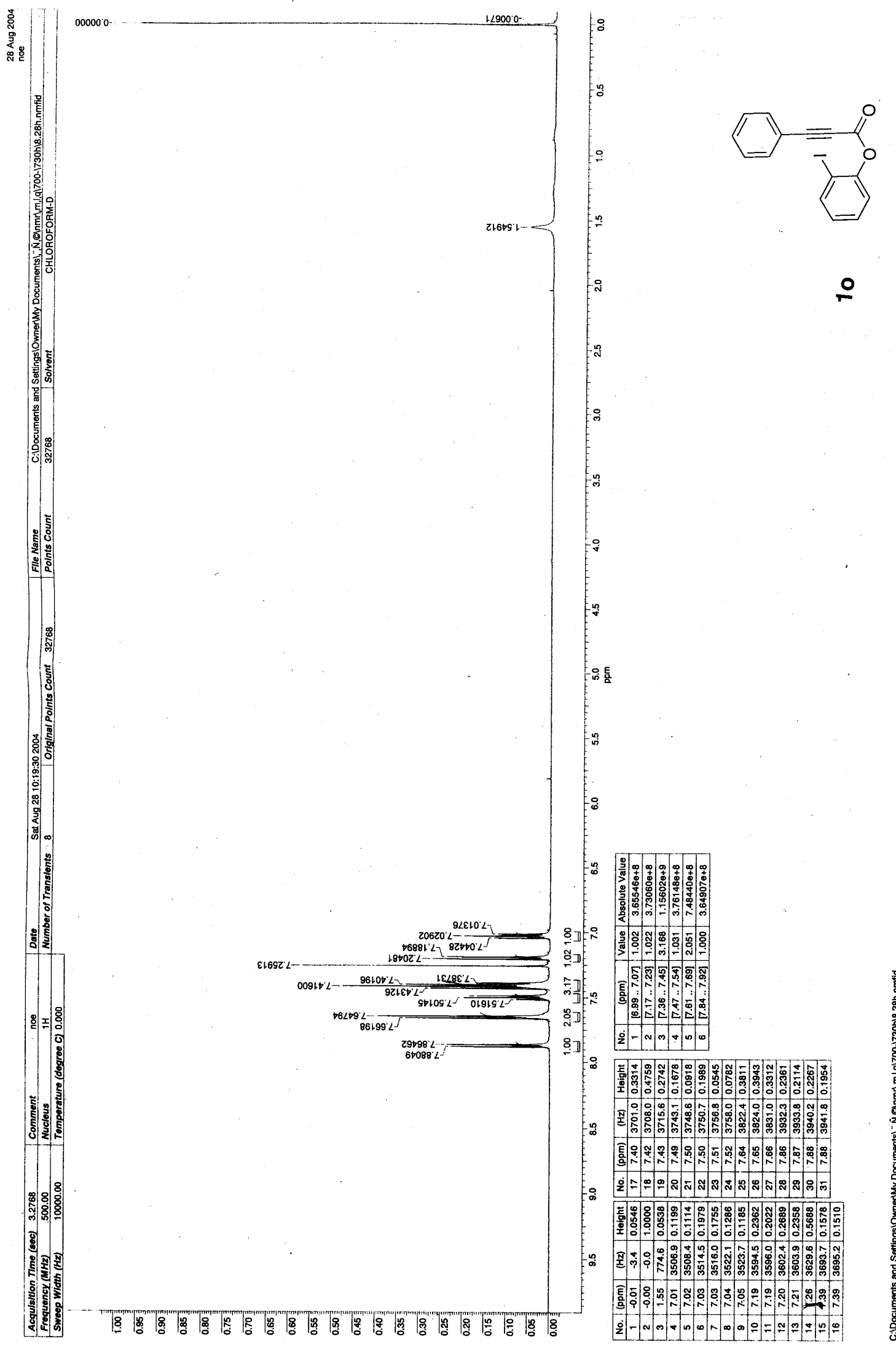




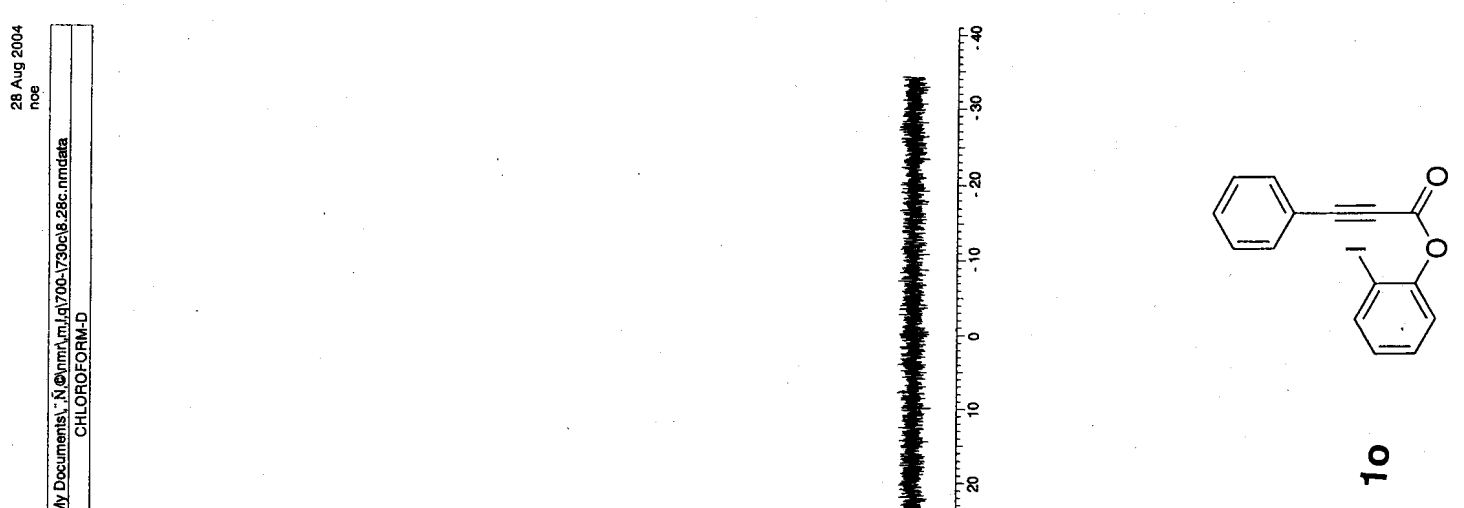

.

$1089 L$
10000

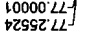

(3)

圁
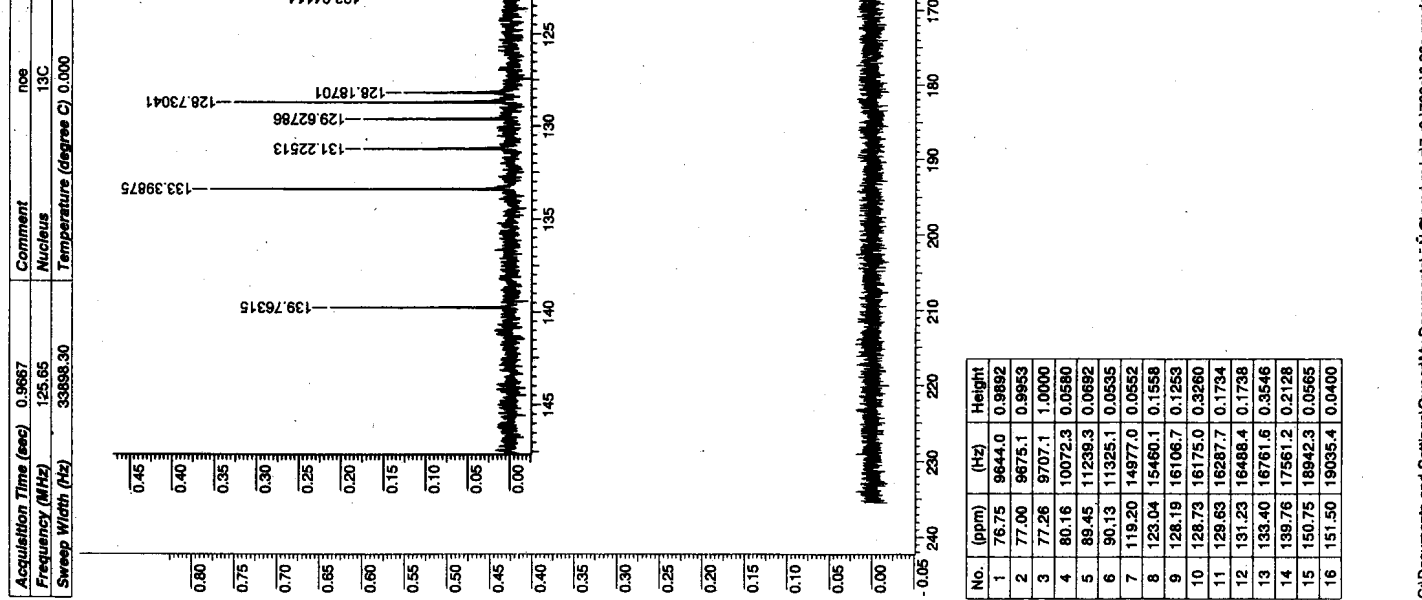


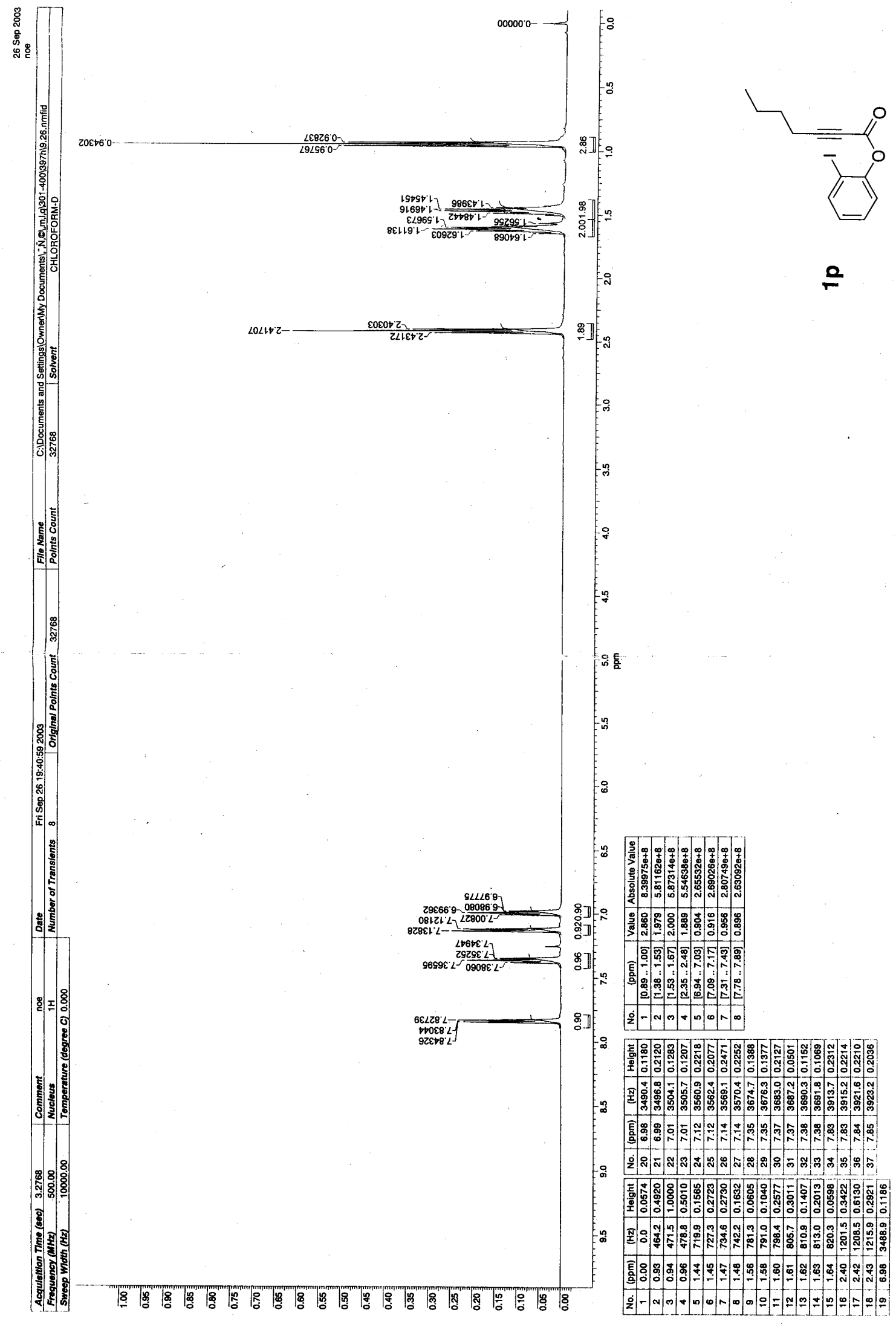




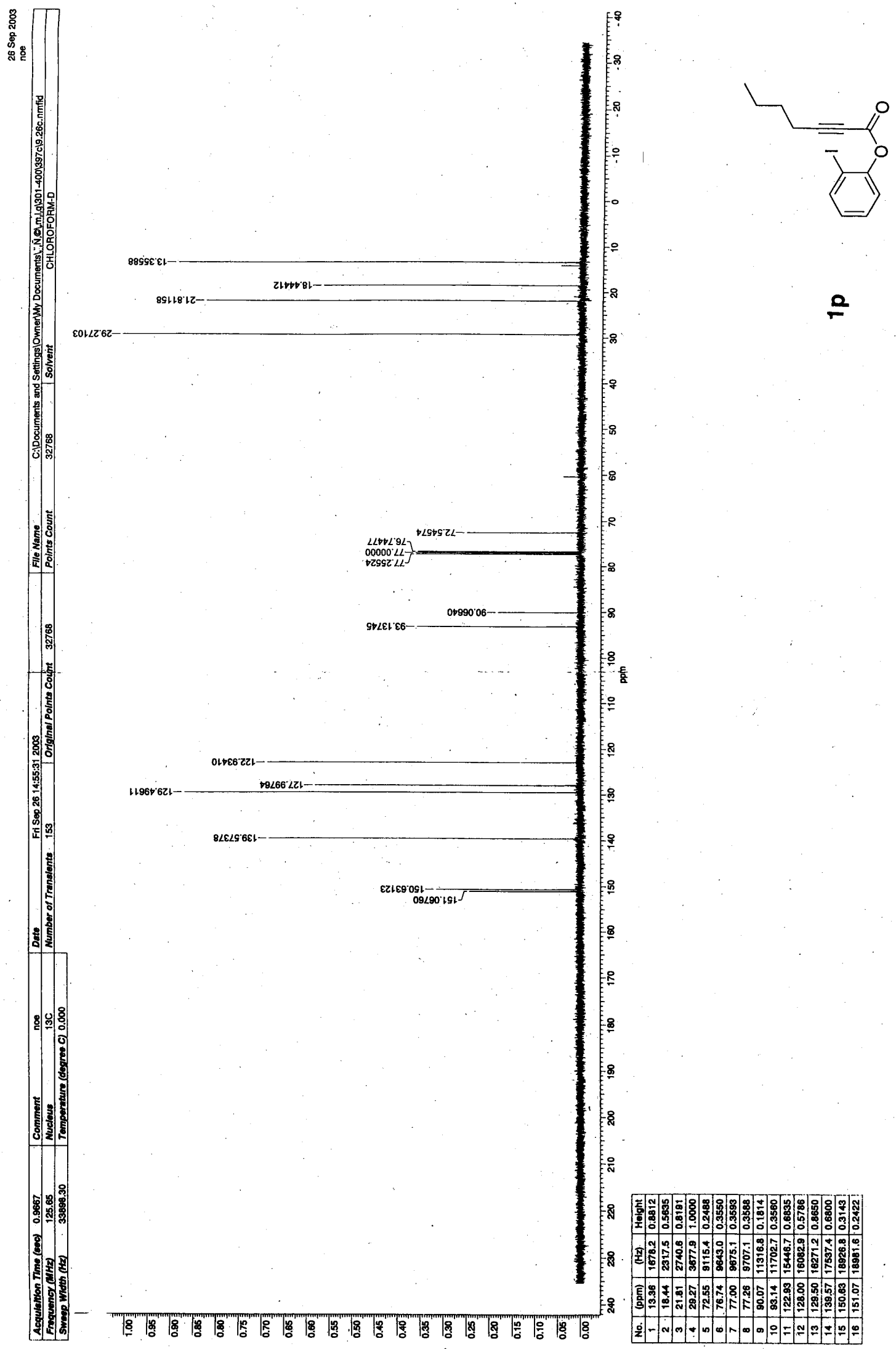




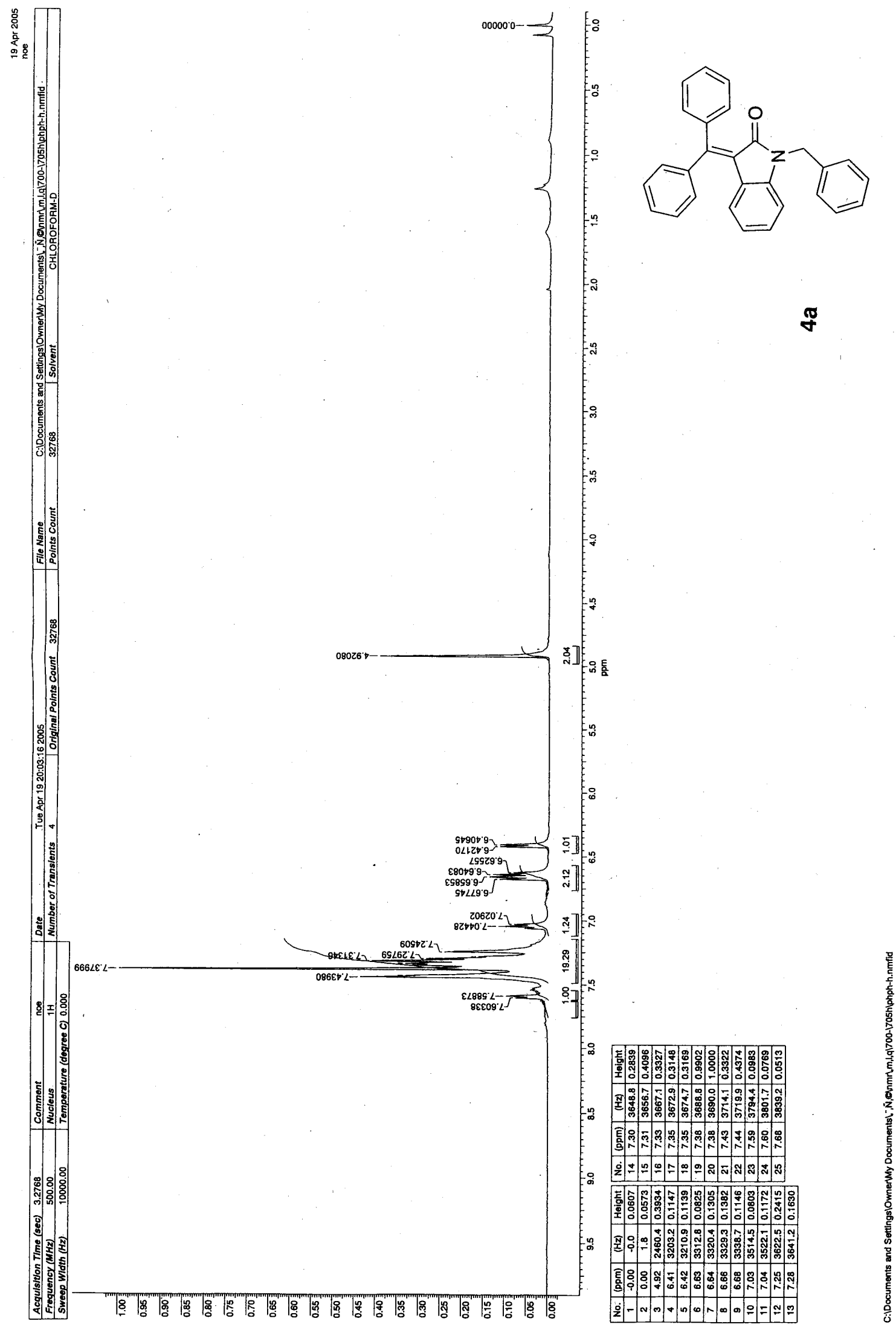




$$
H
$$




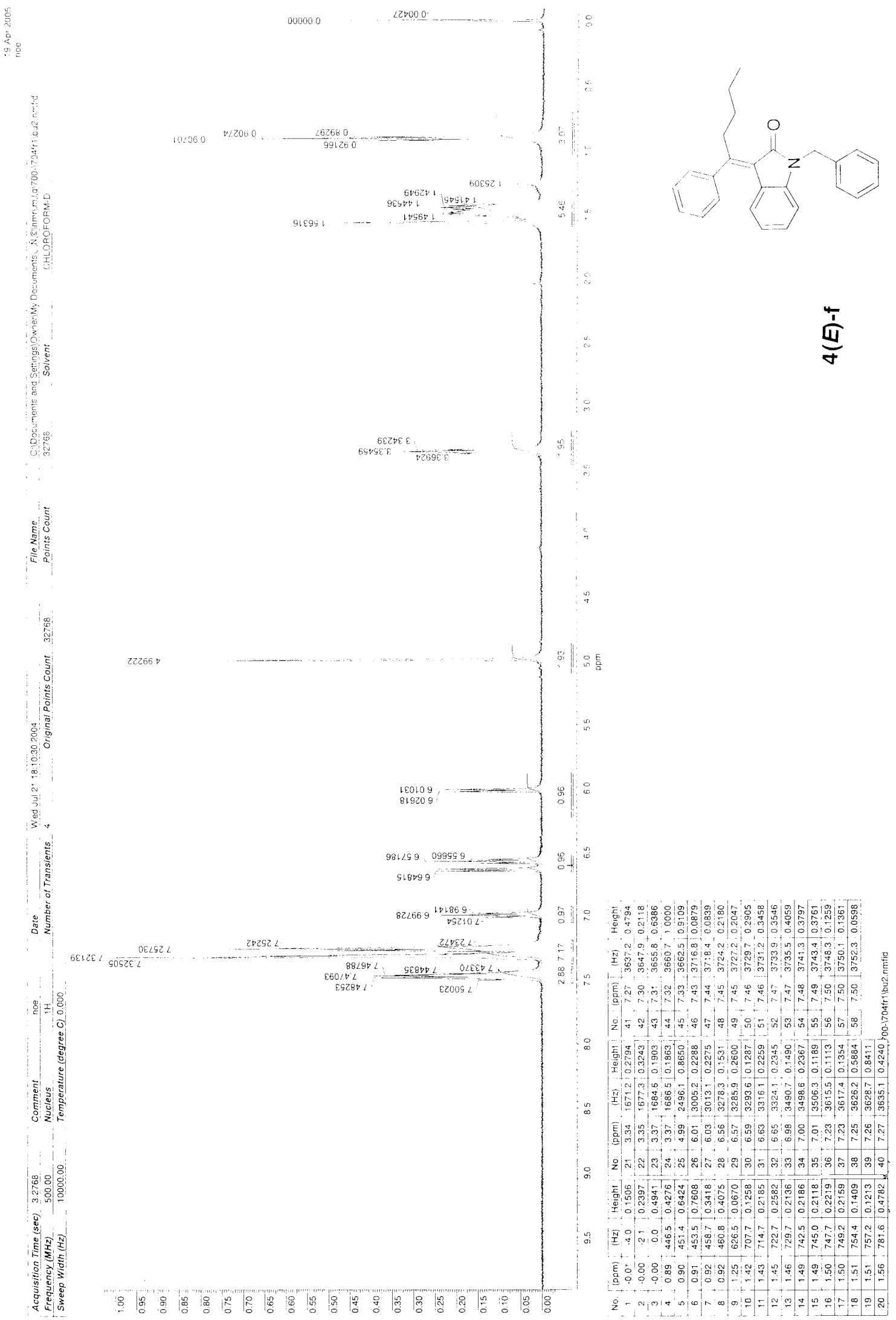




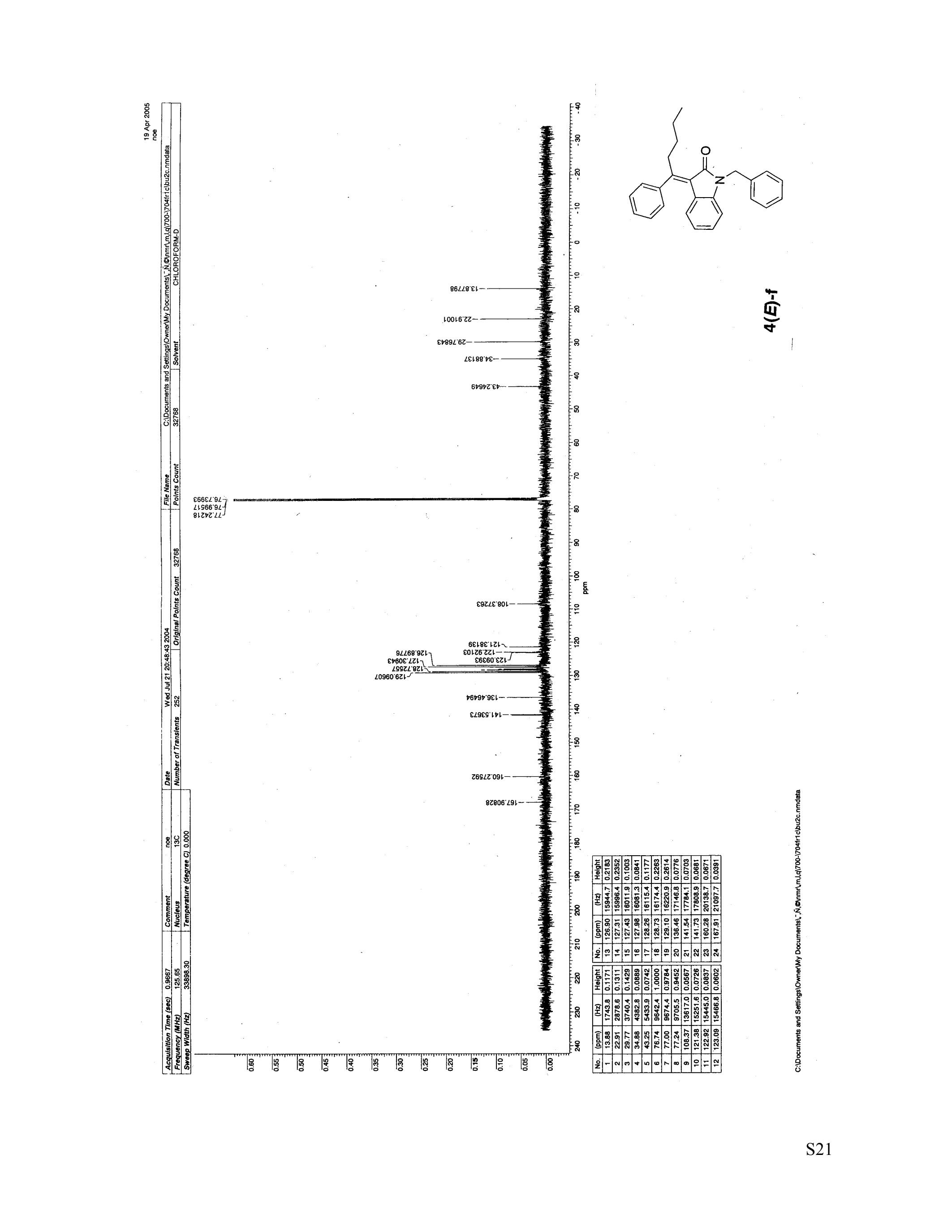




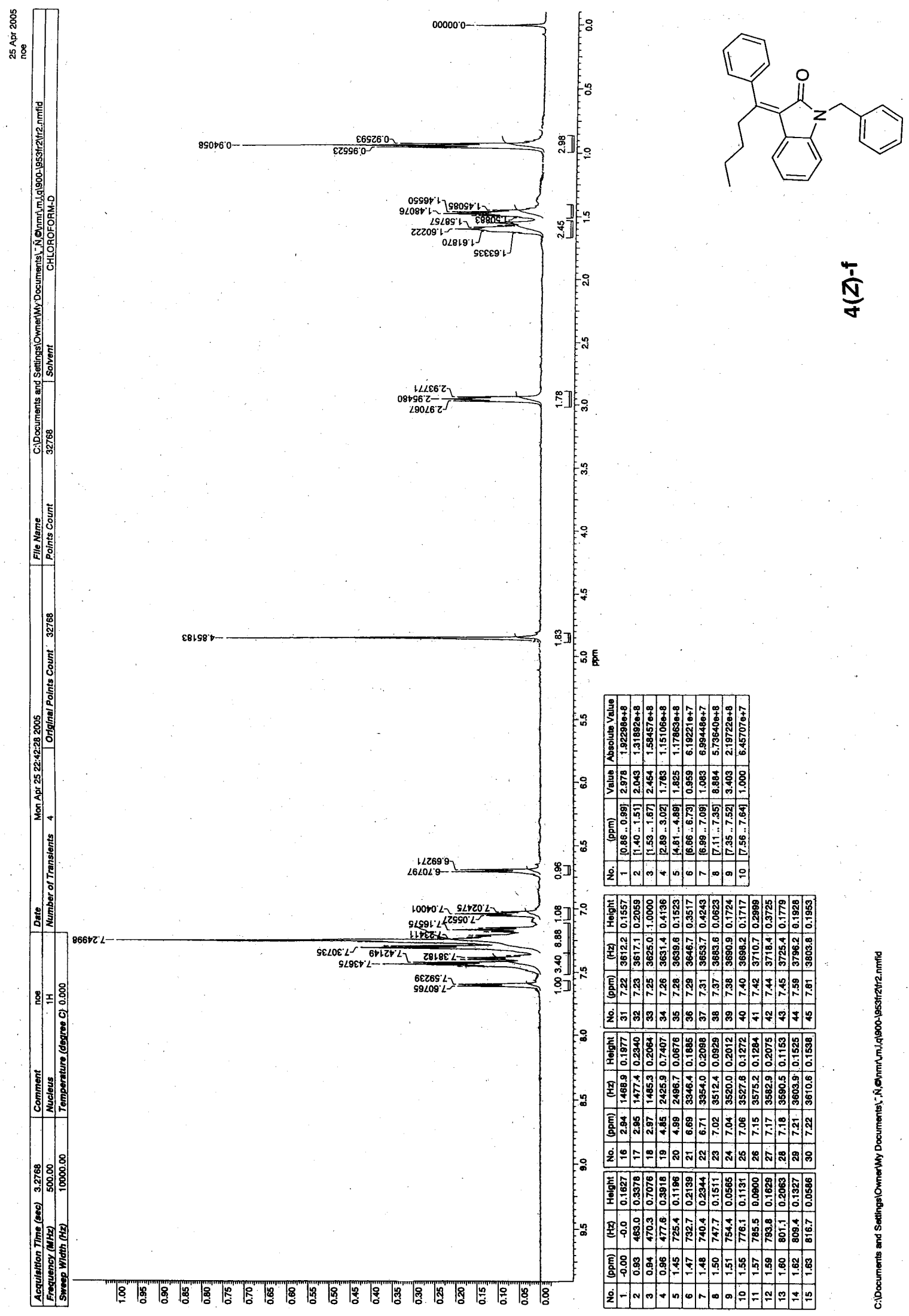




$$
H^{\prime \prime}
$$




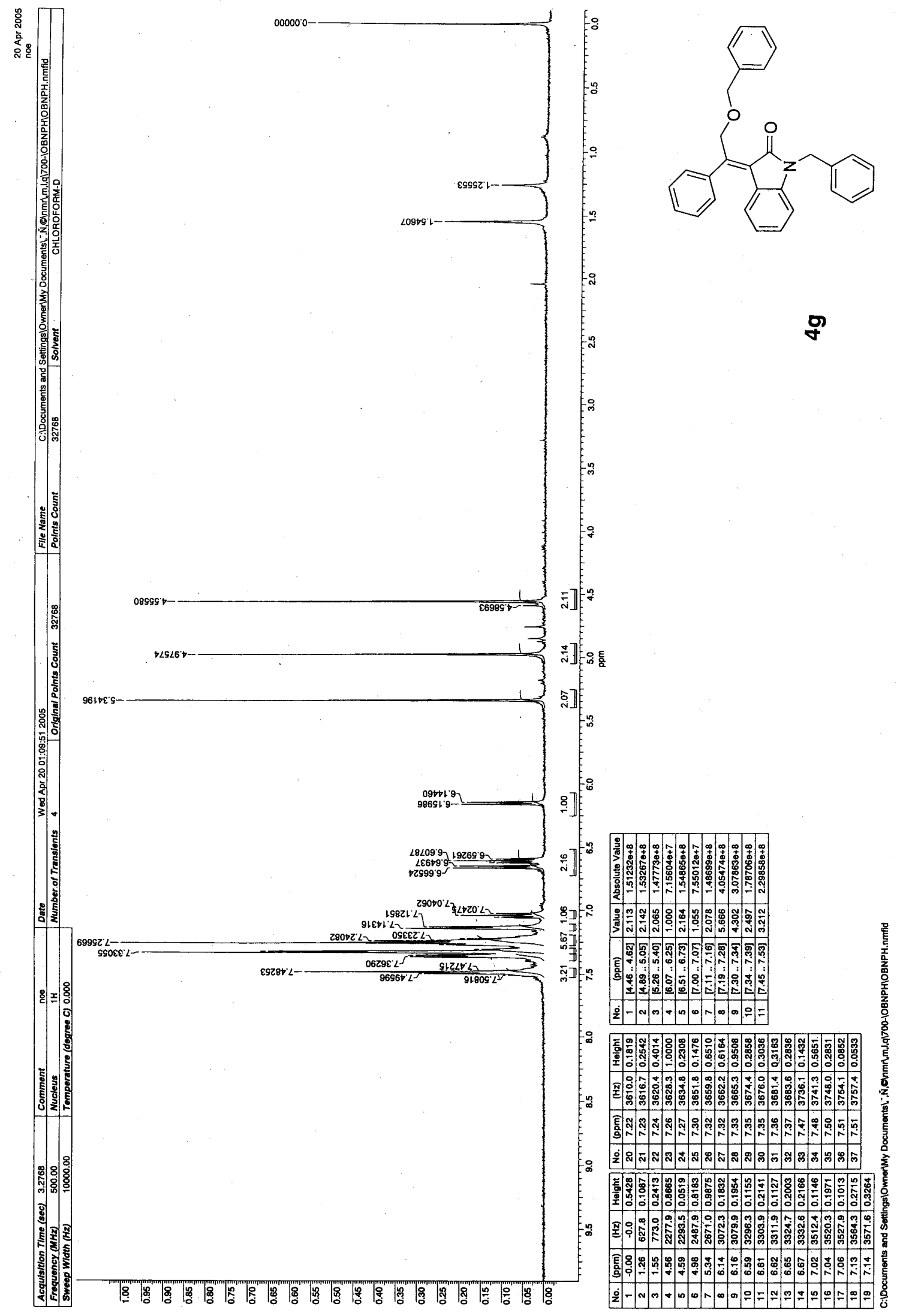




$$
H
$$




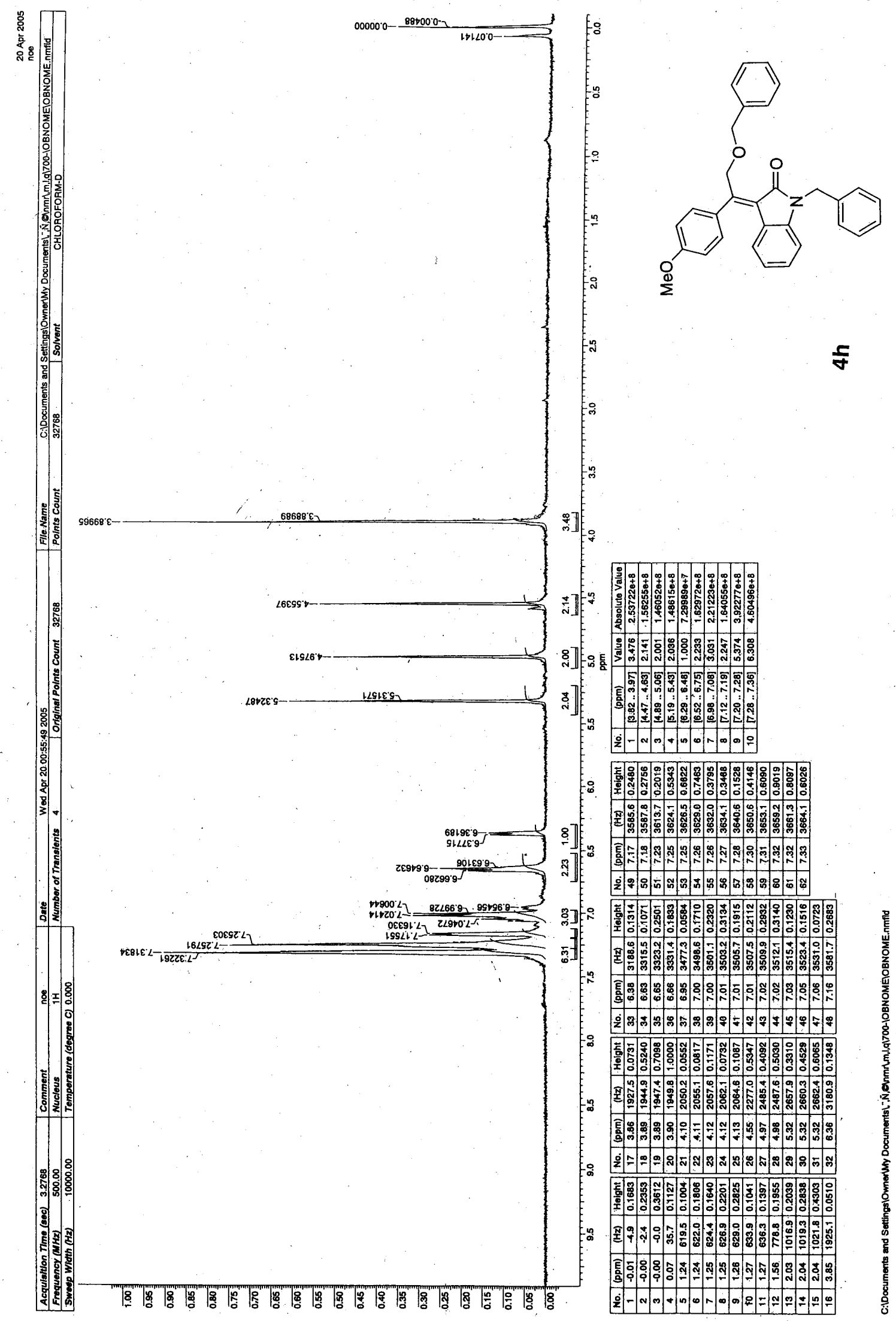









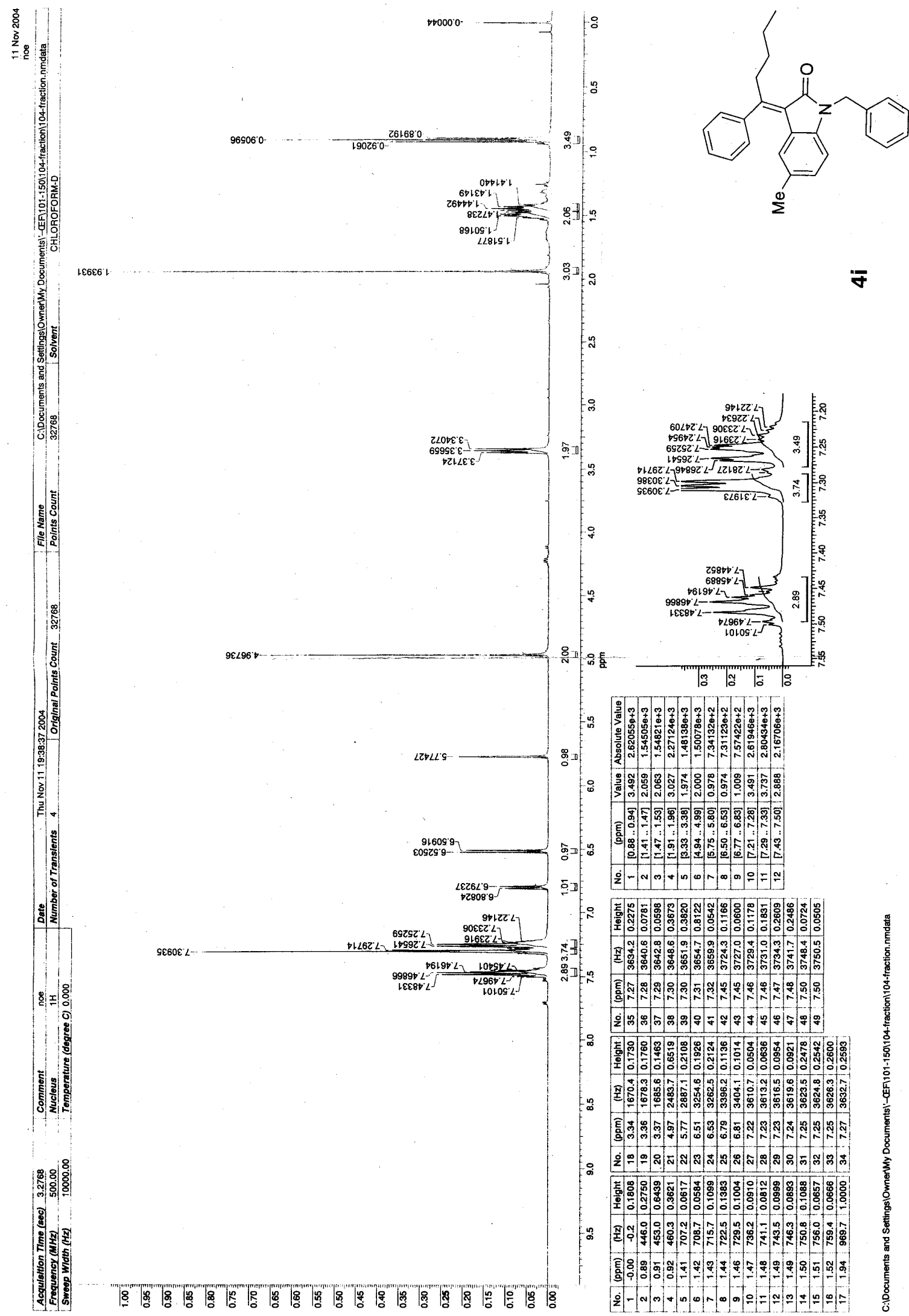




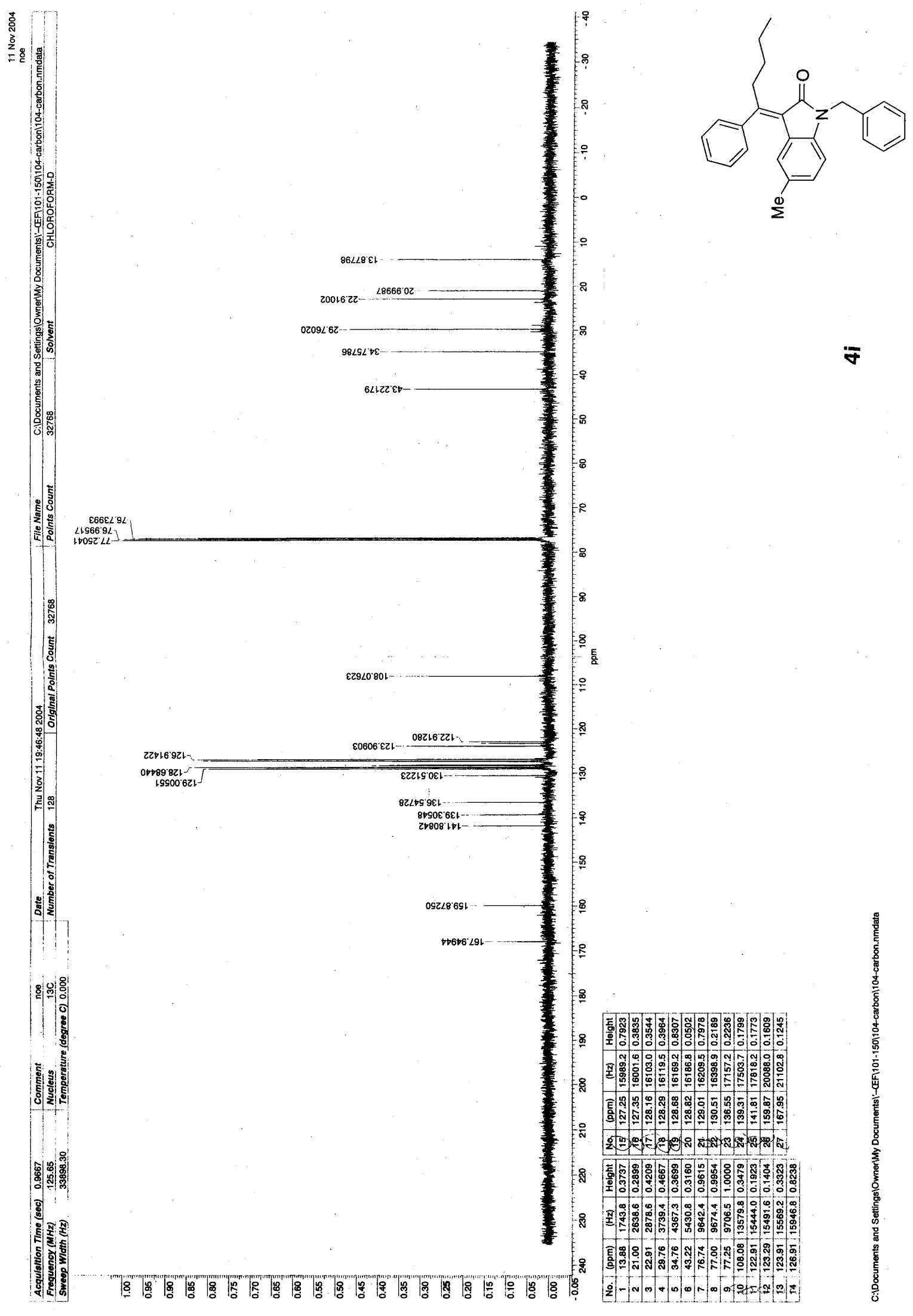

S29 


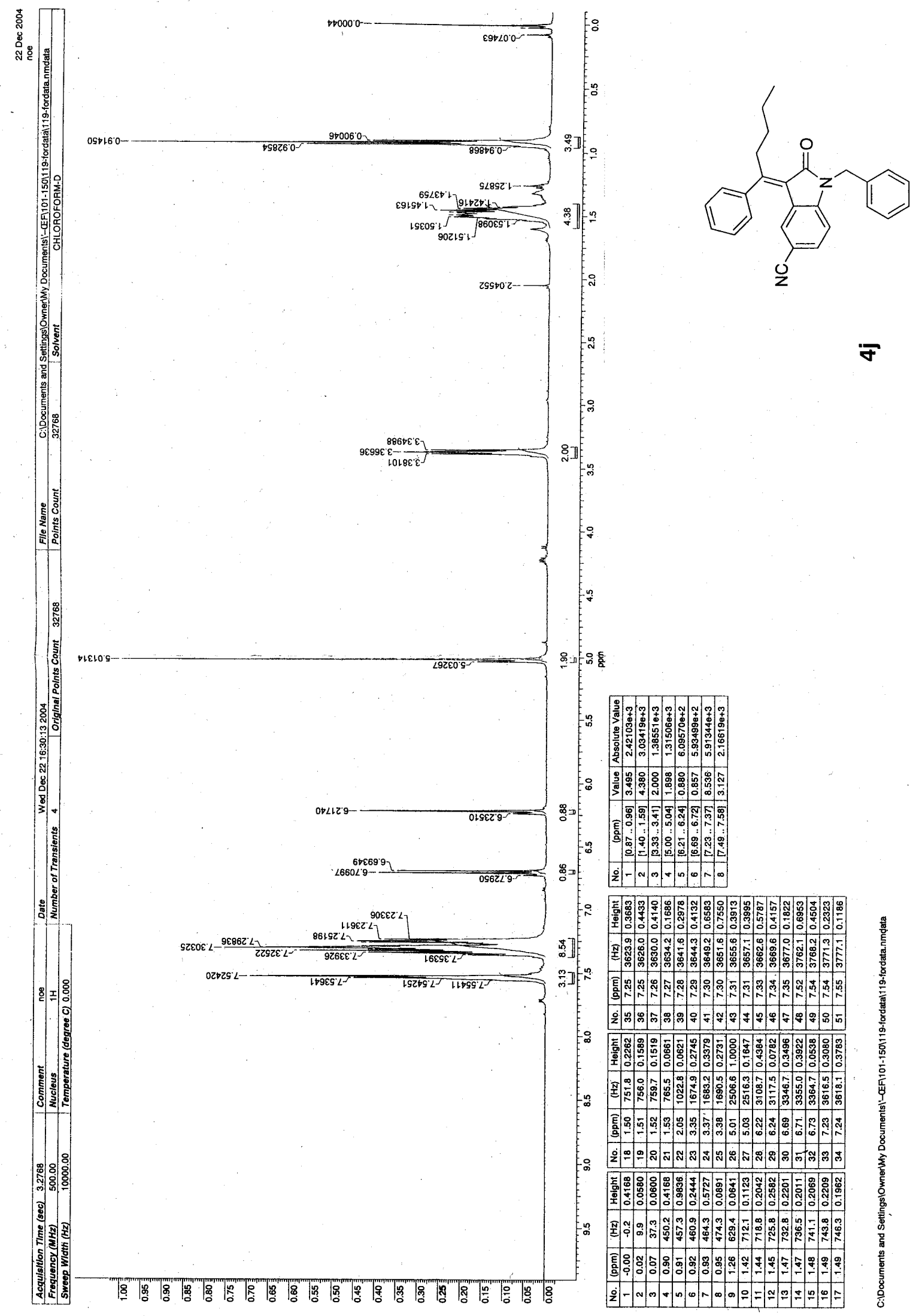




$$
H
$$




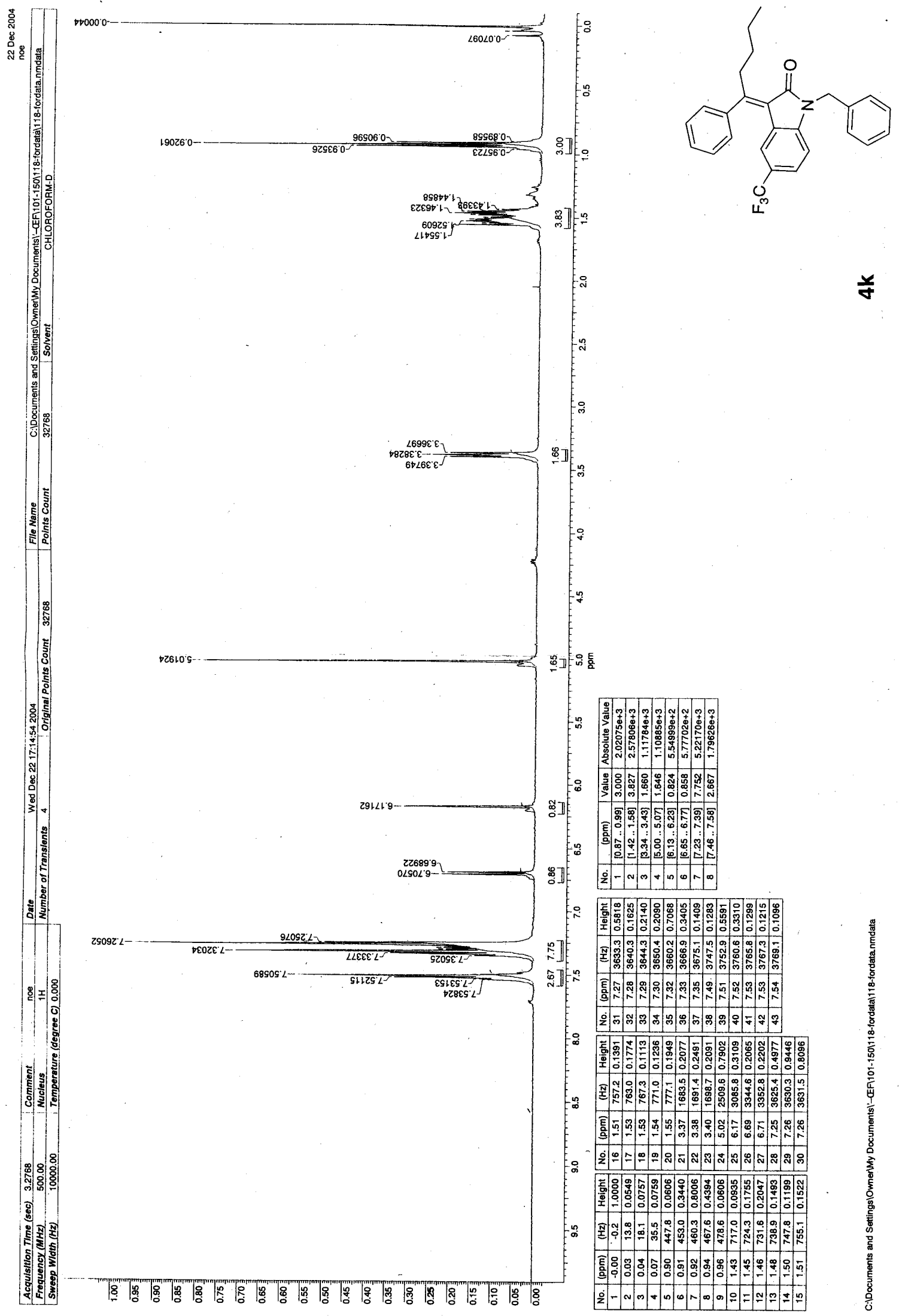




$$
1
$$




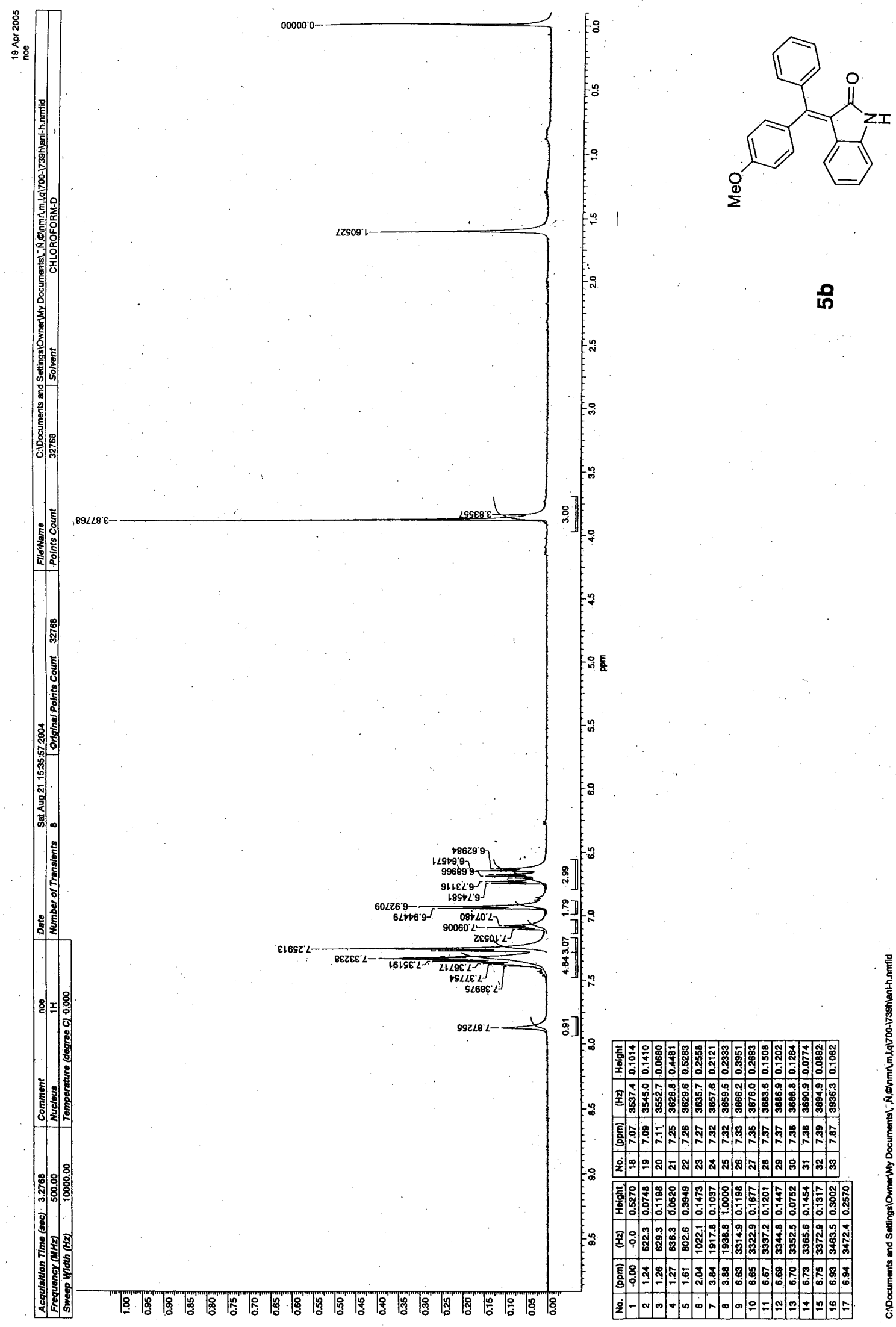




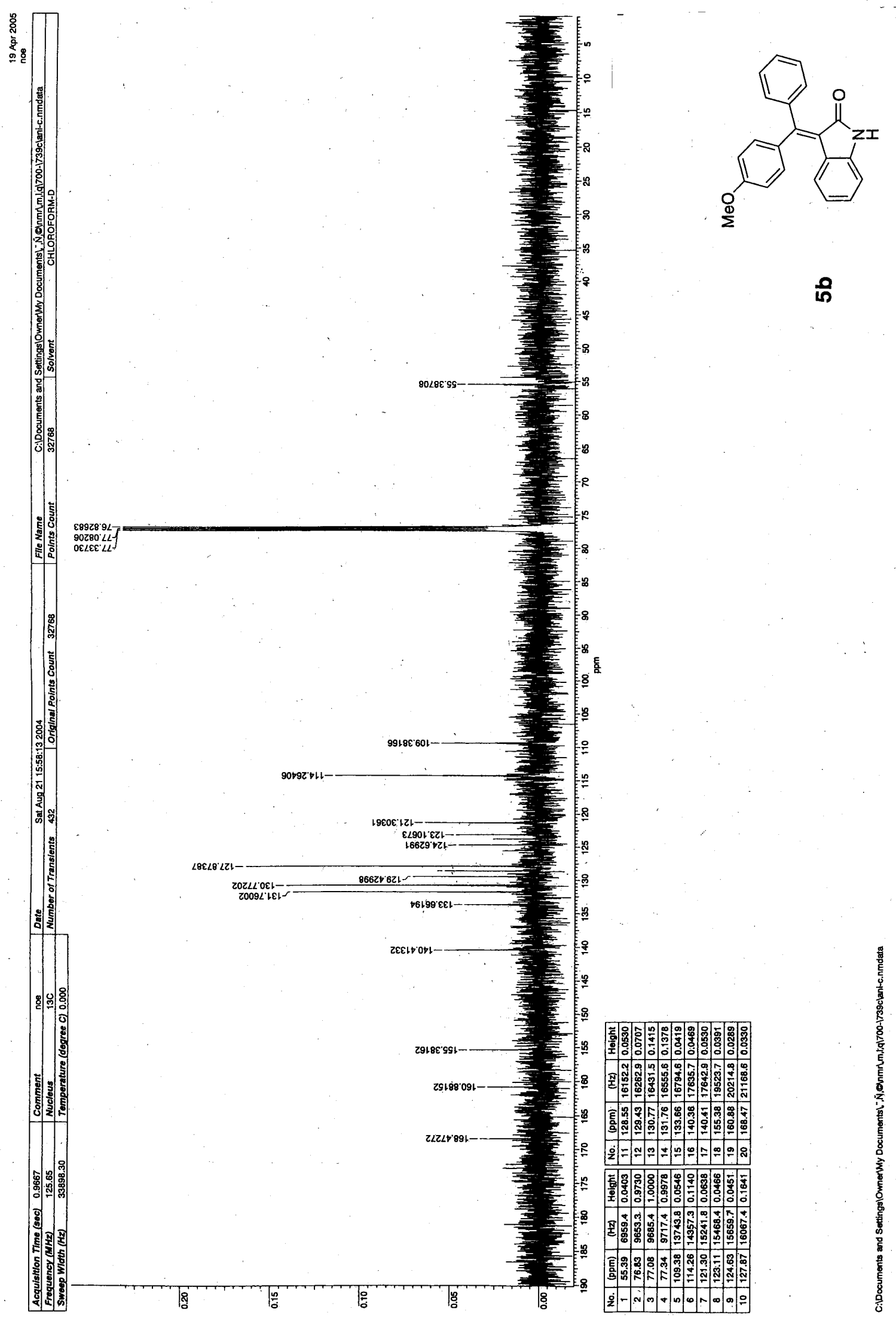




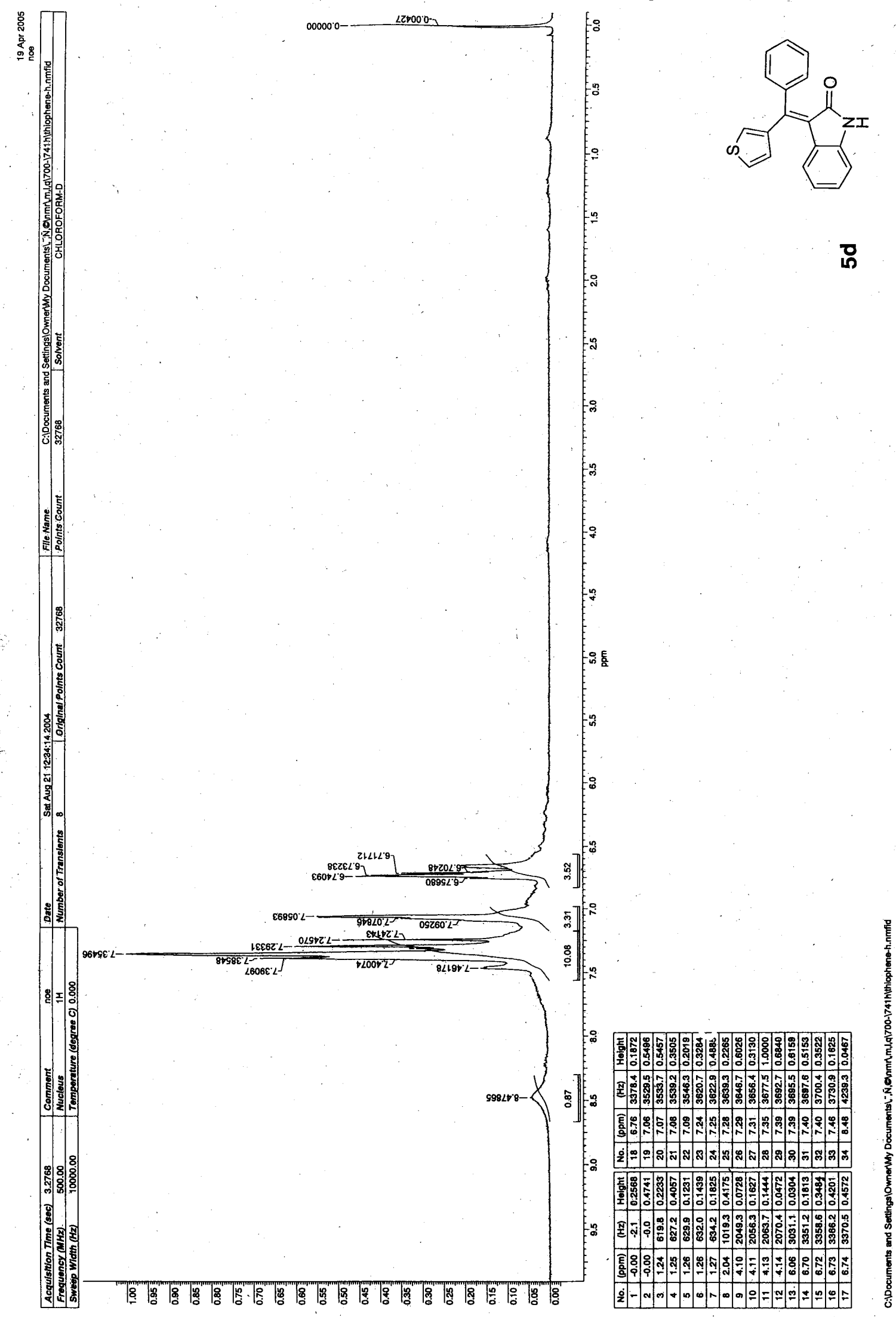




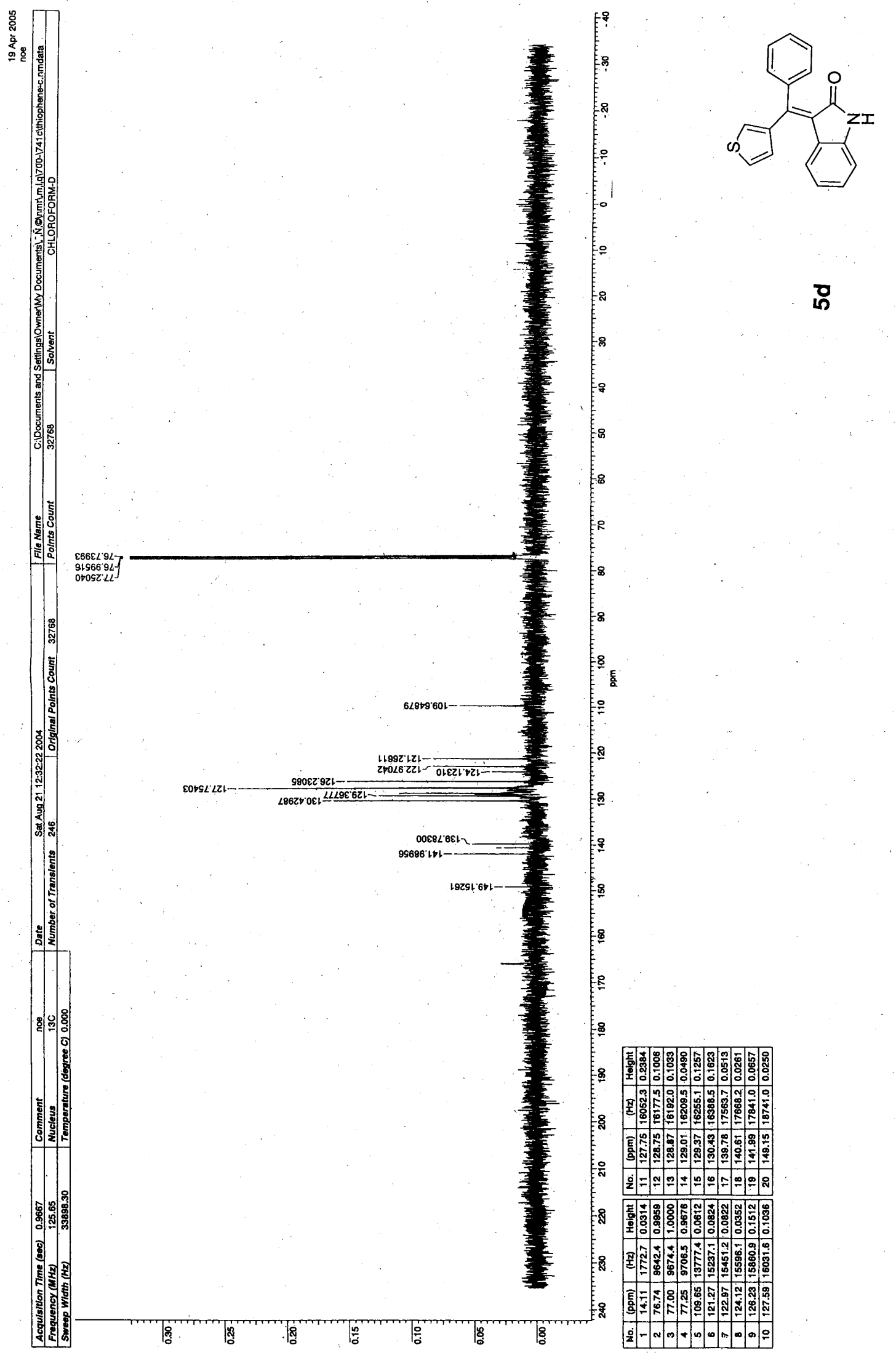









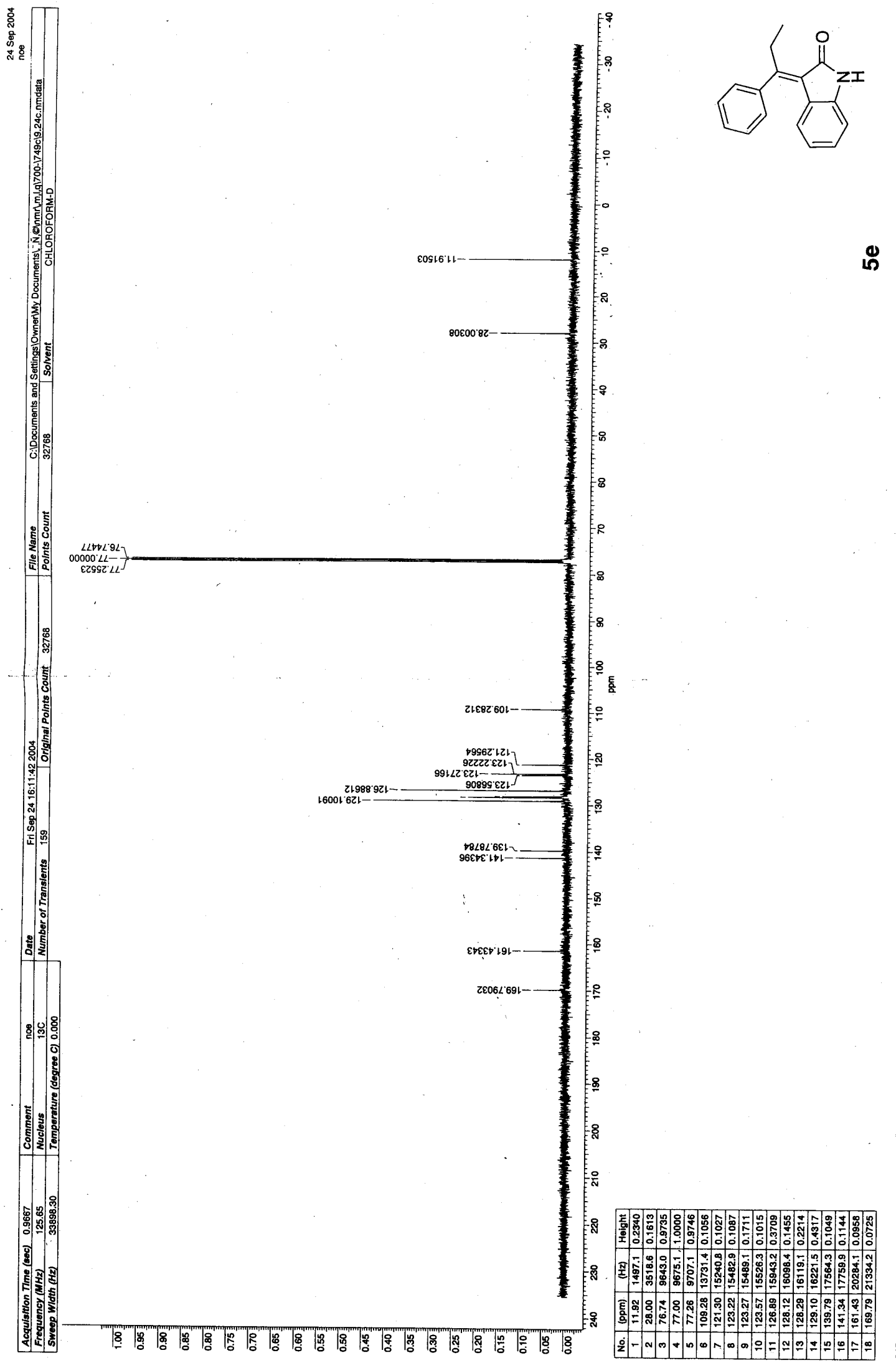




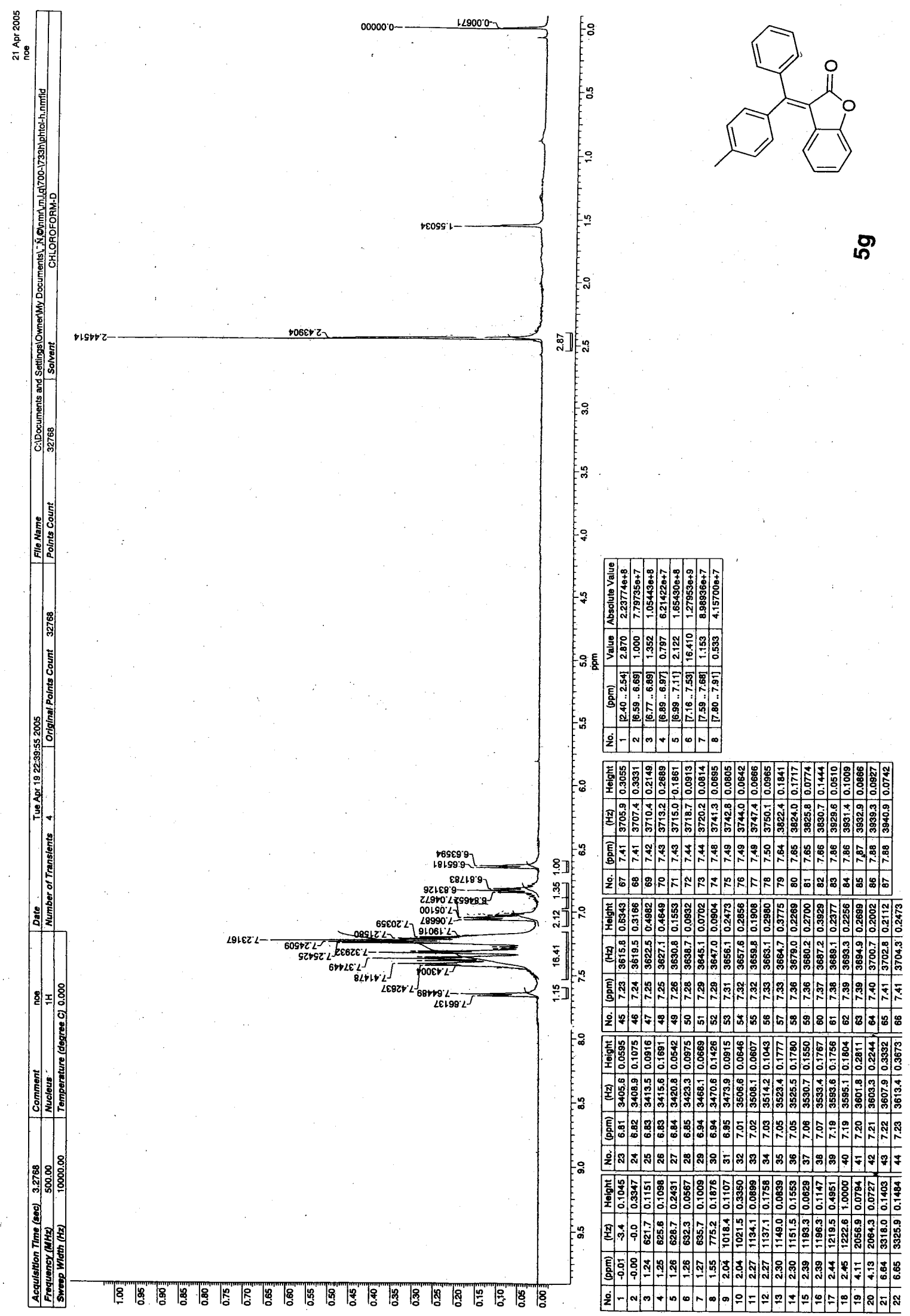




$$
H
$$




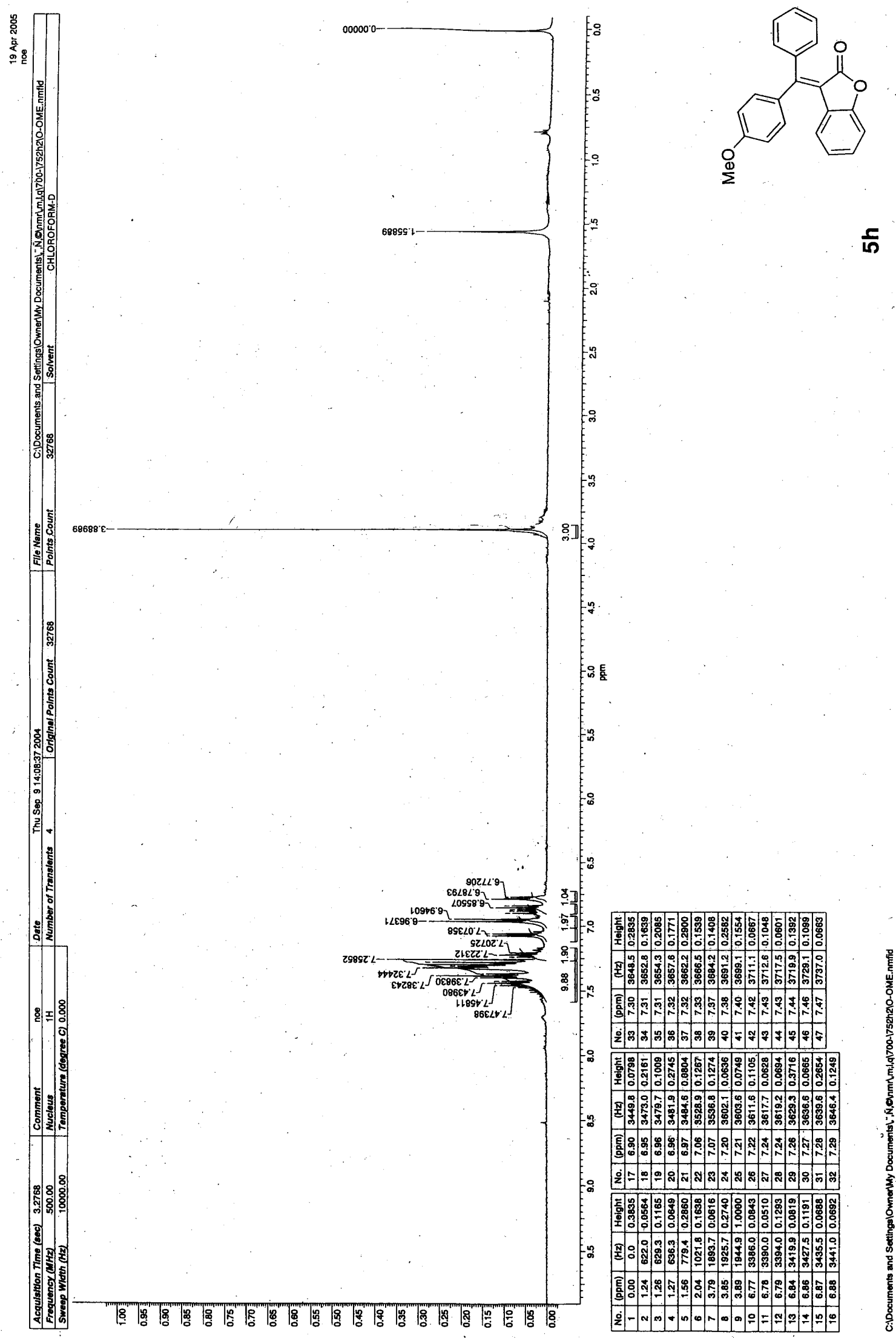




$$
H
$$




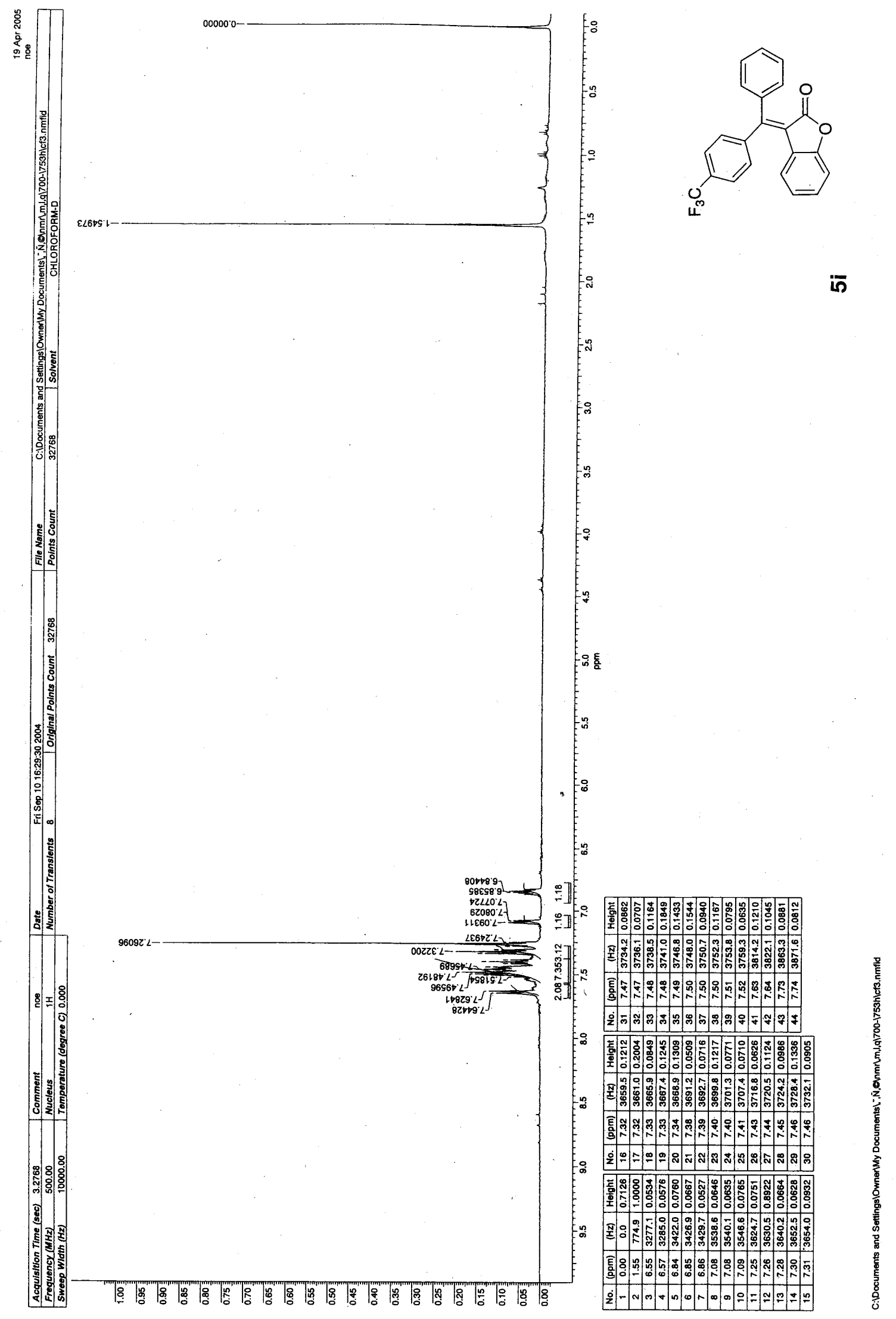




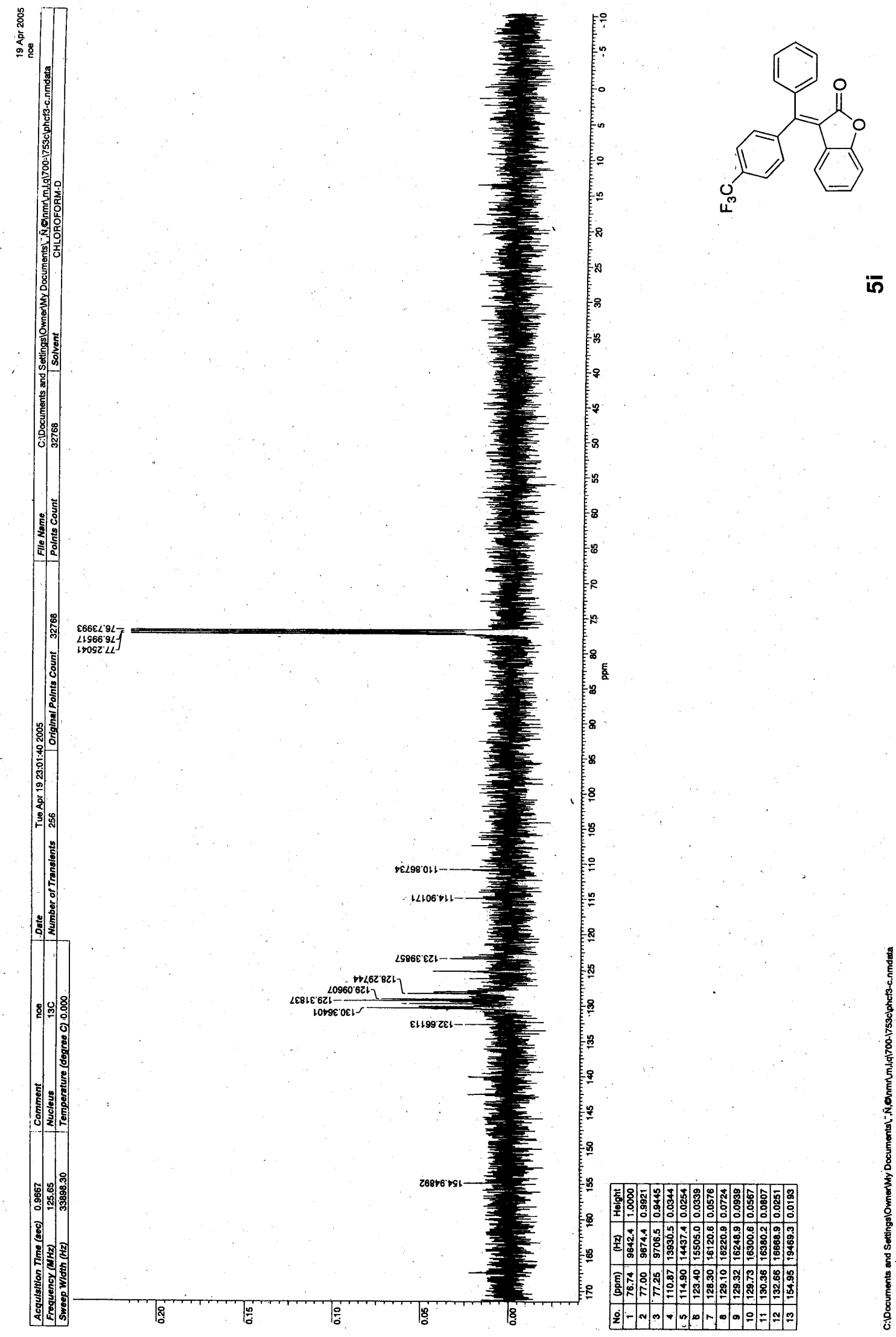




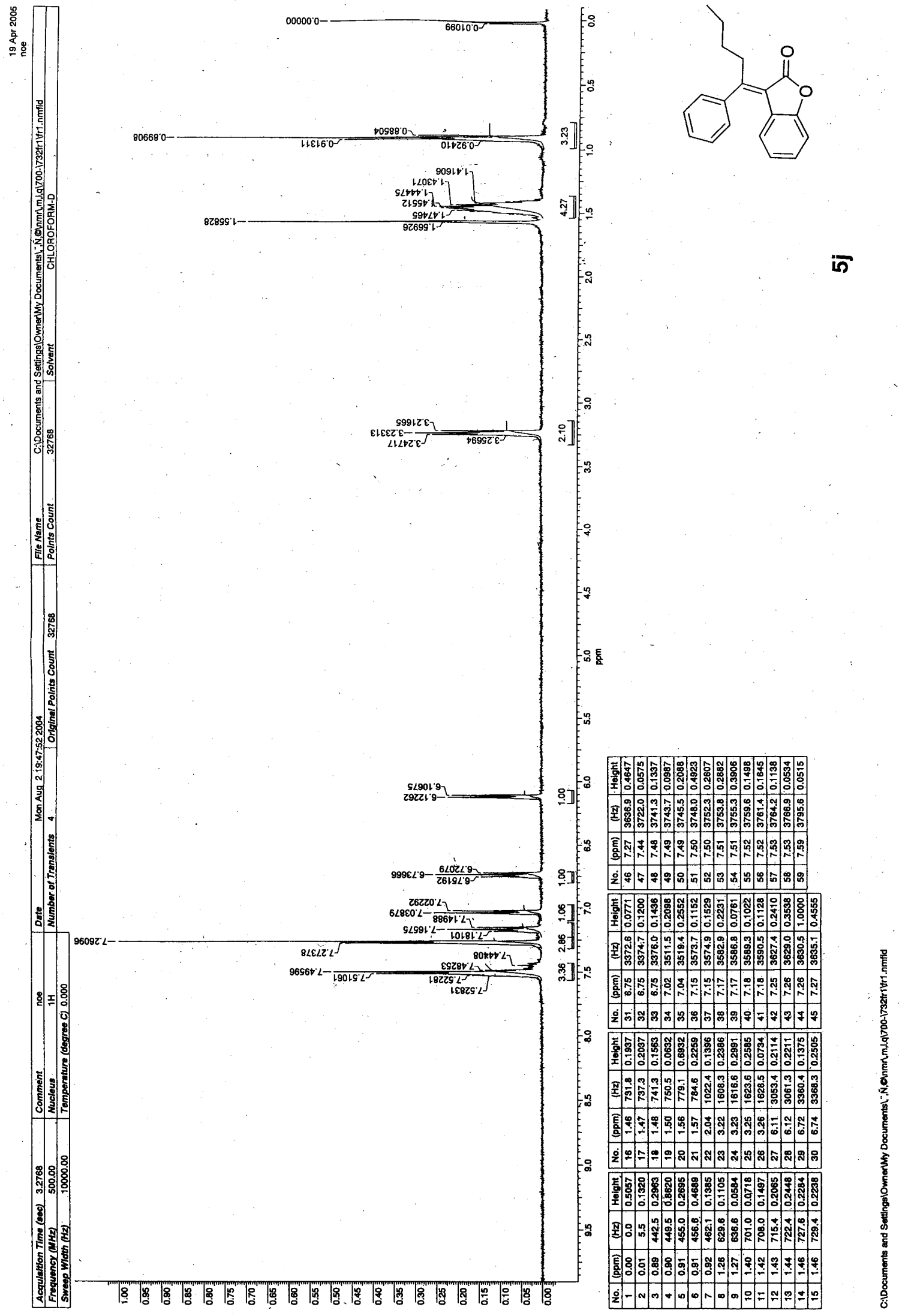



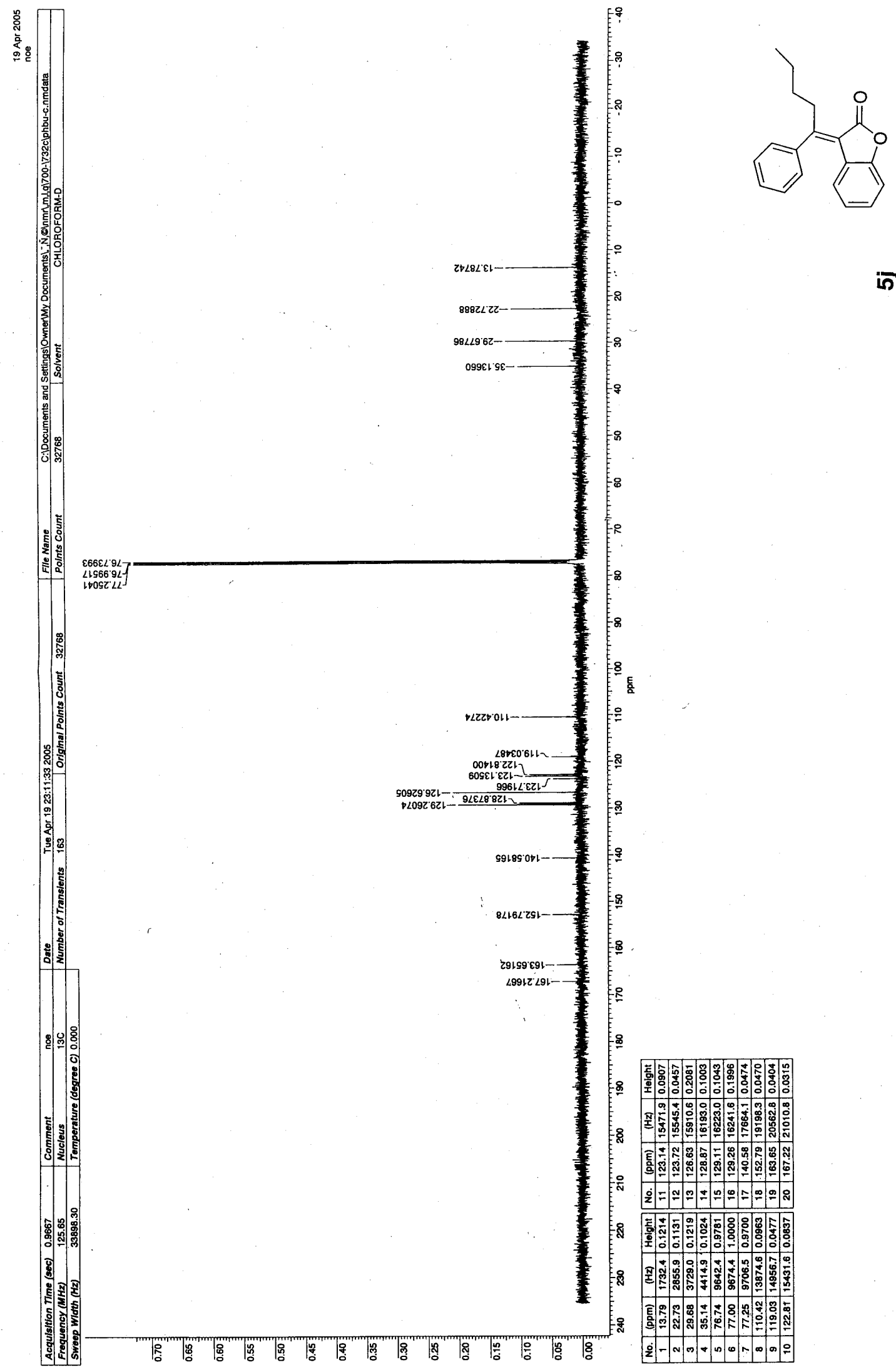

เ 


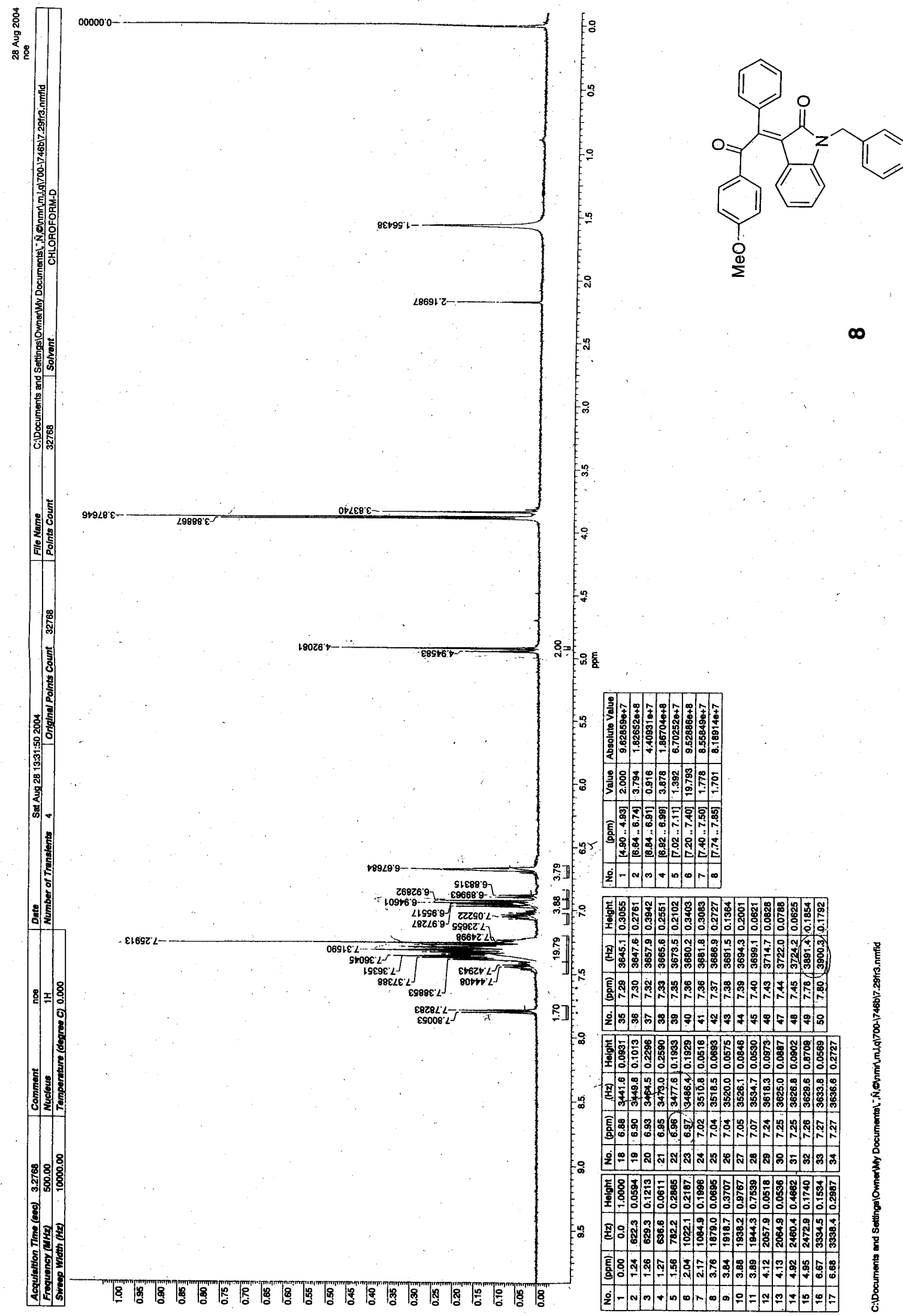




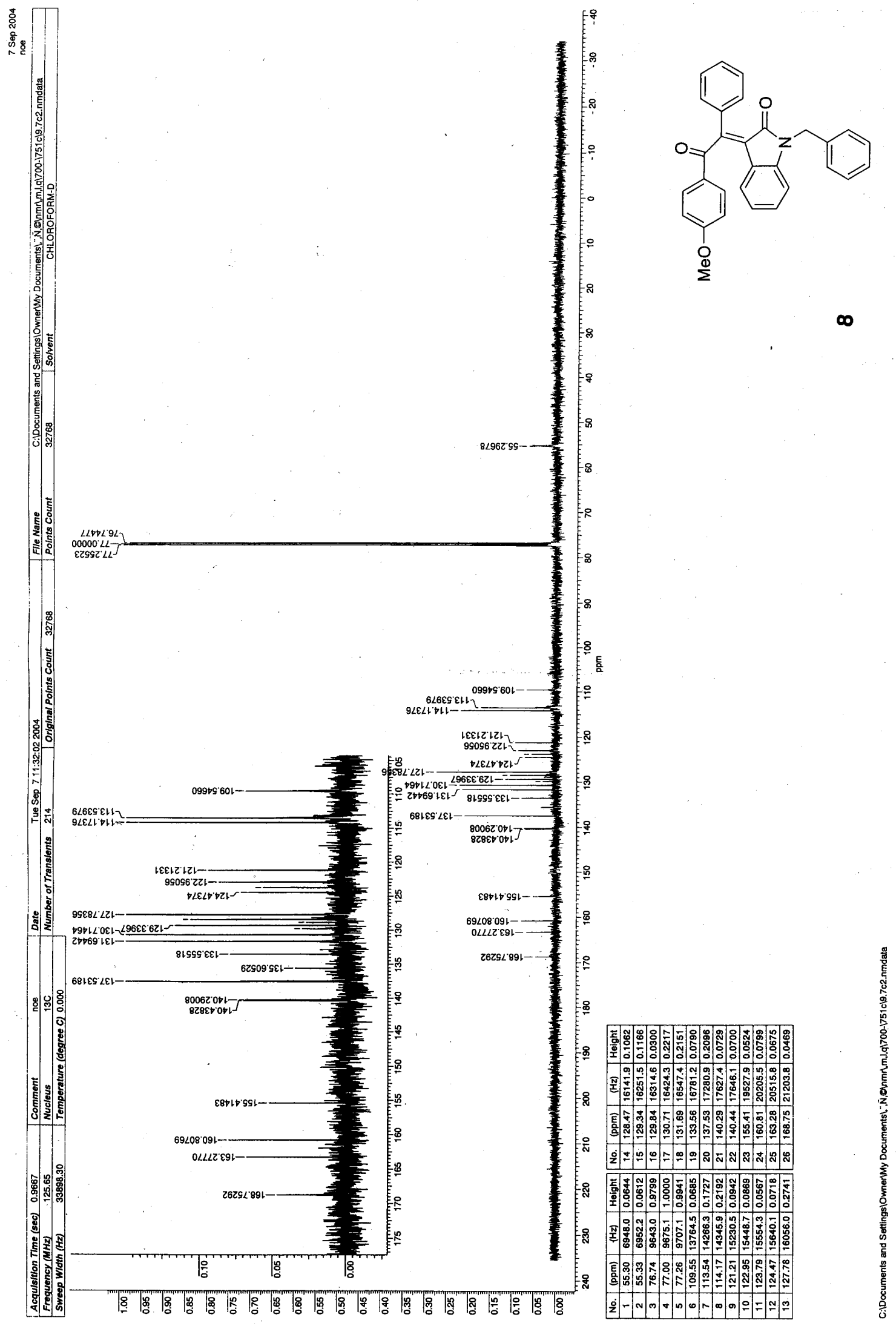




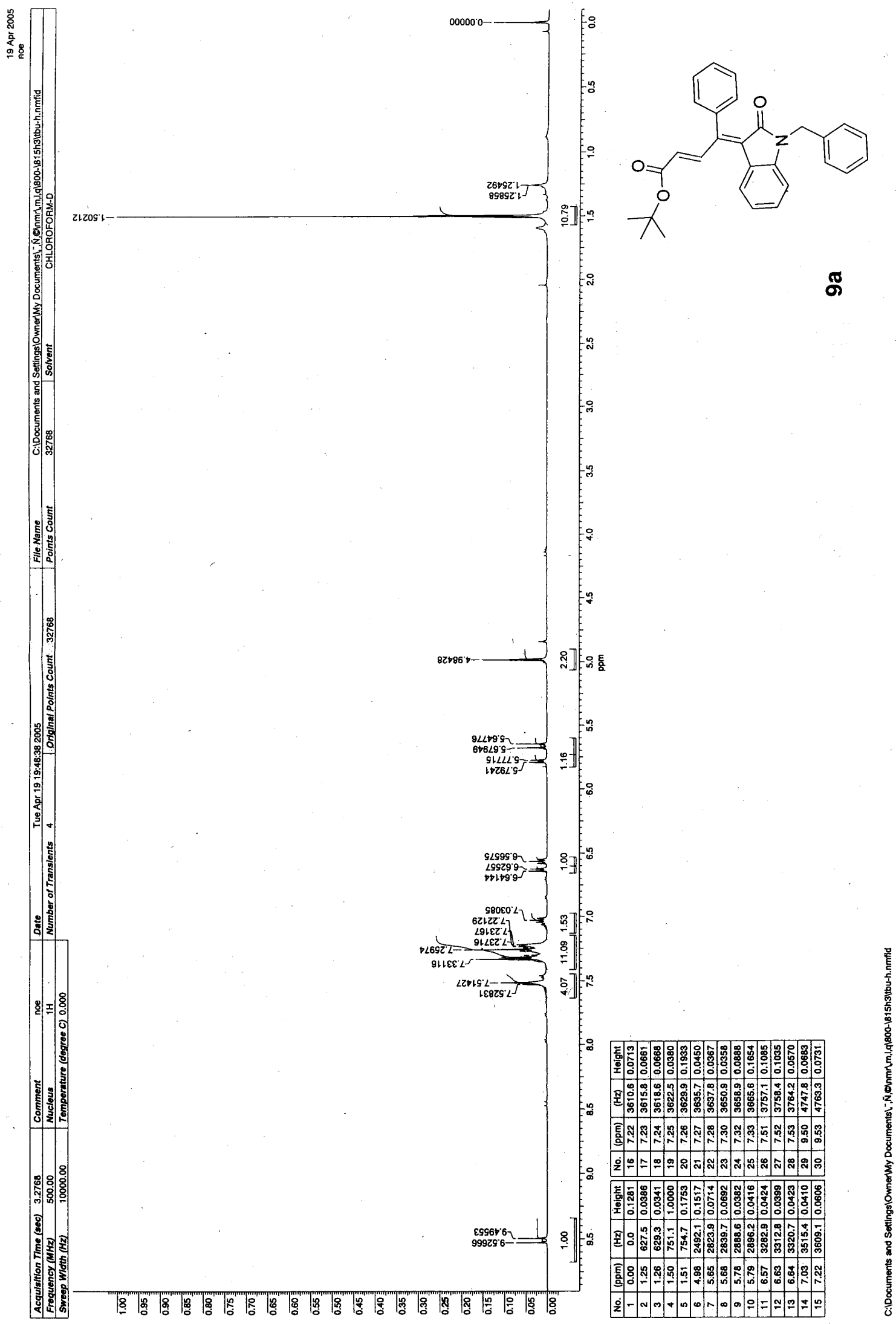




$$
H
$$




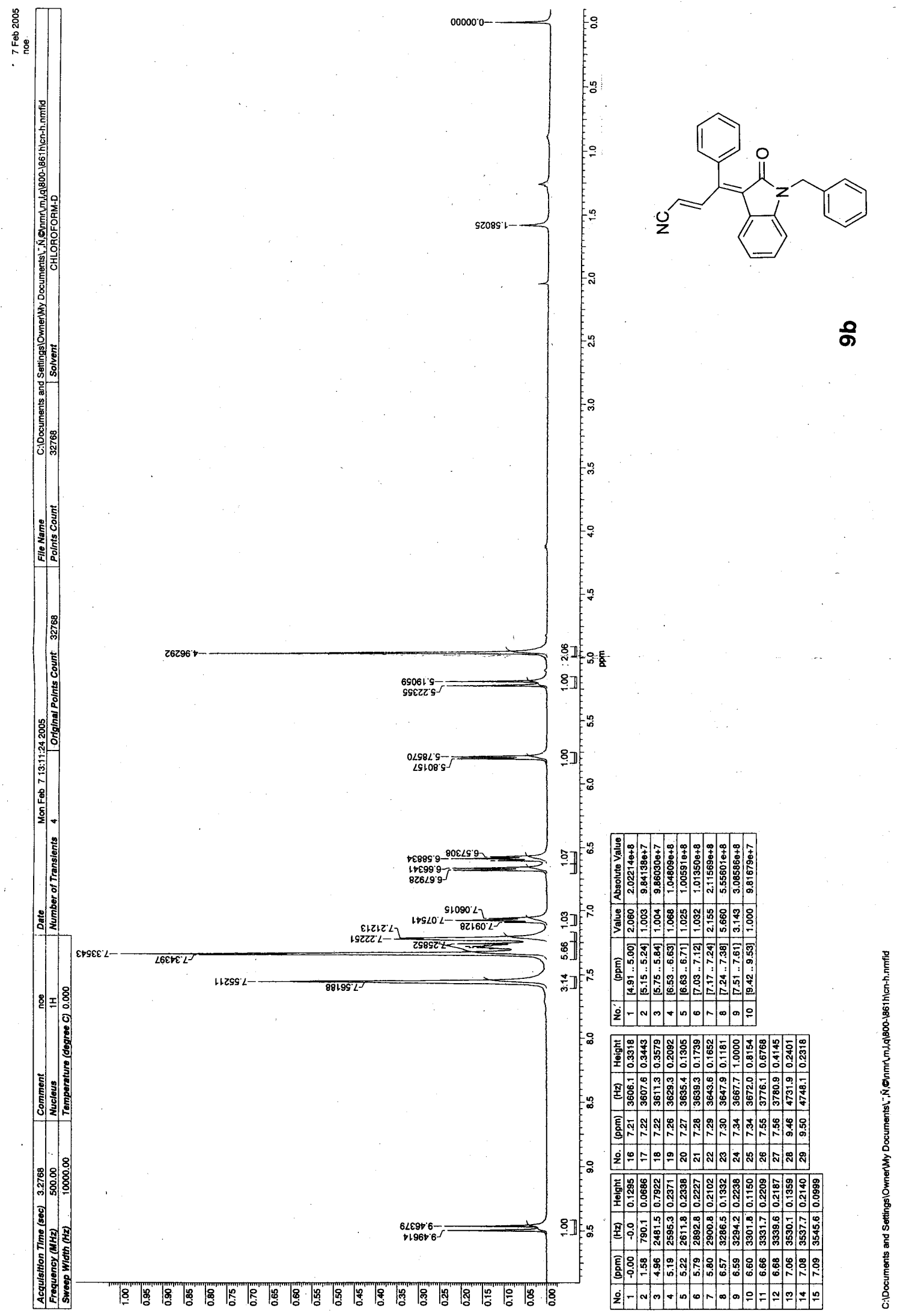




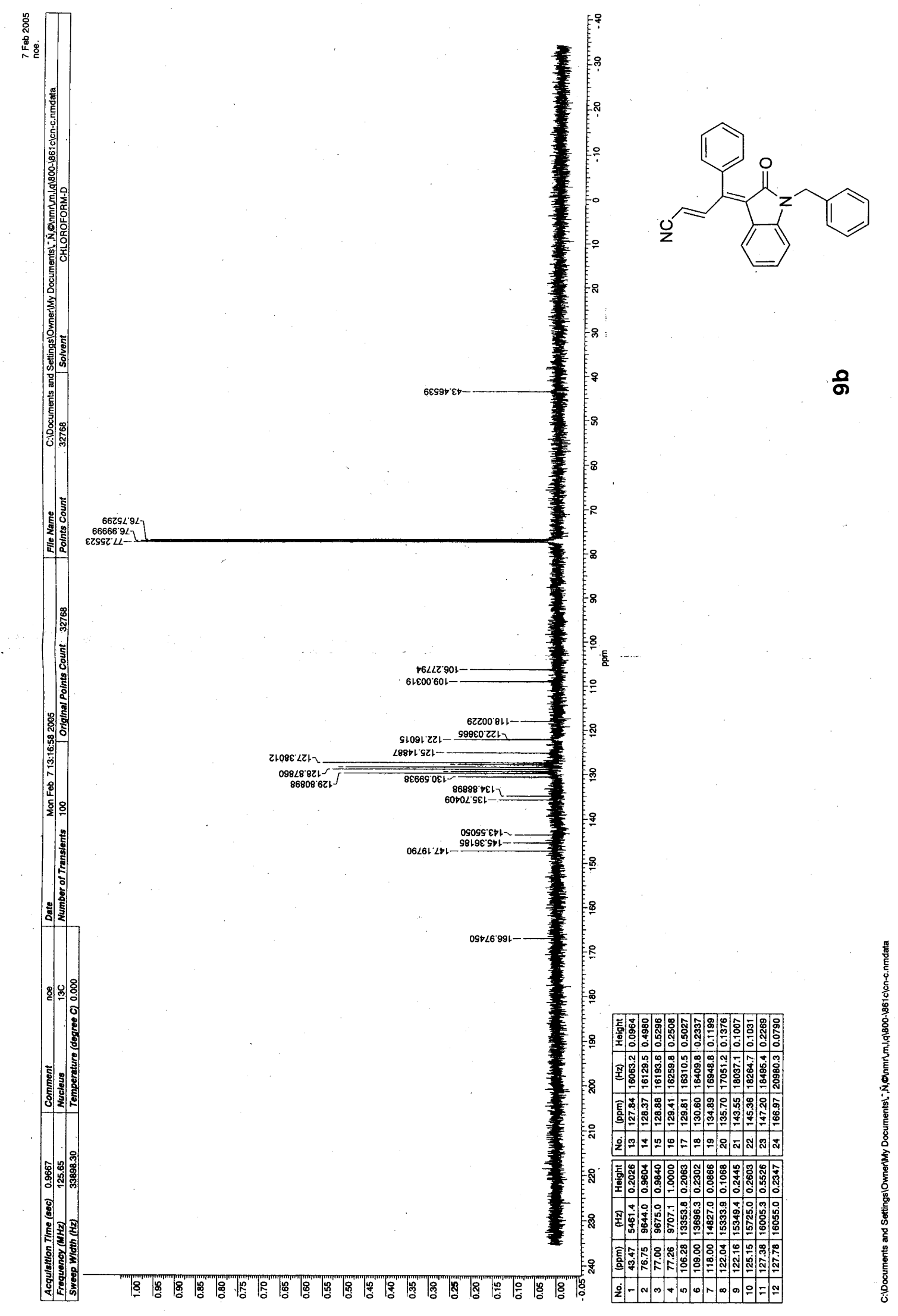




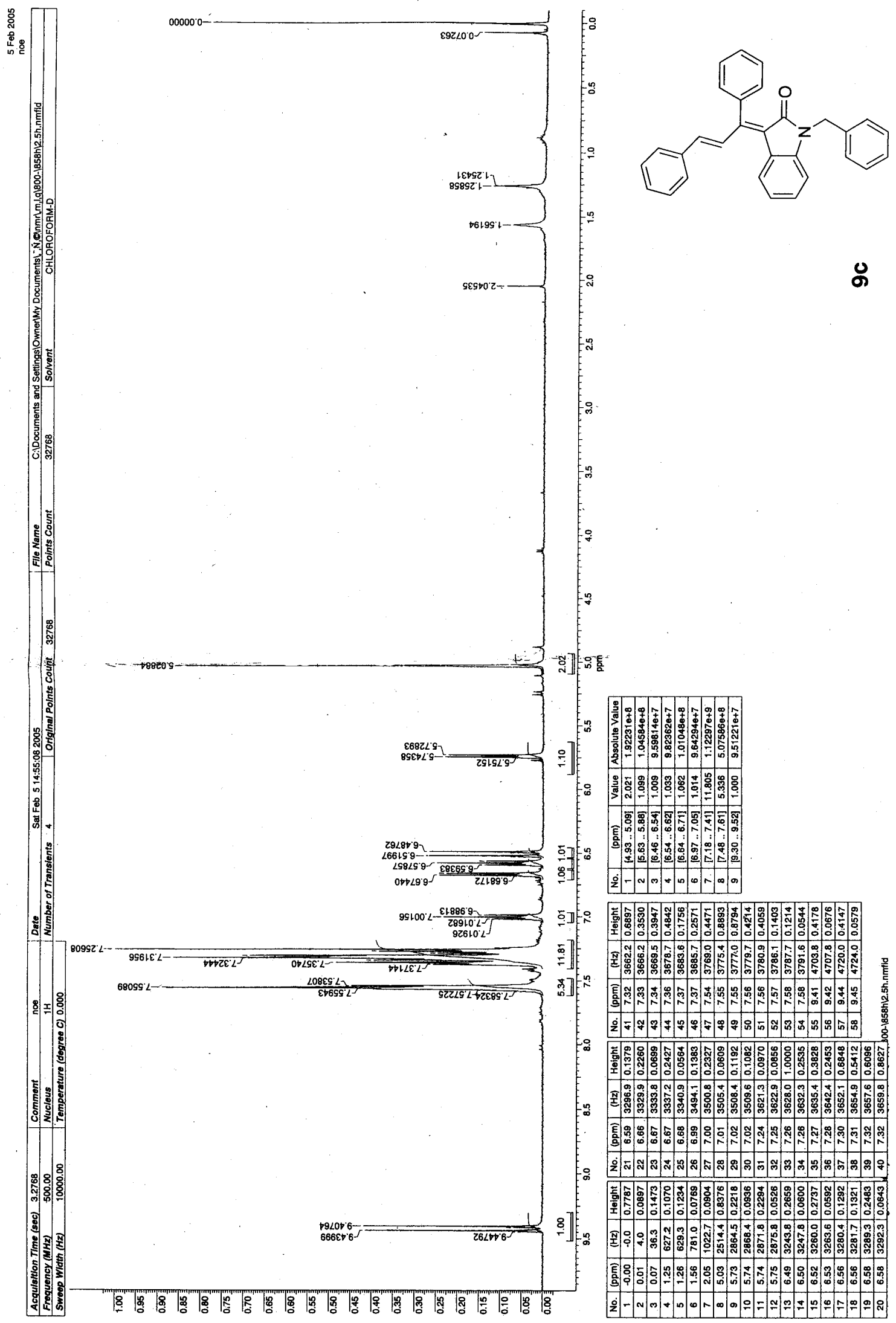




$$
\text { A }
$$




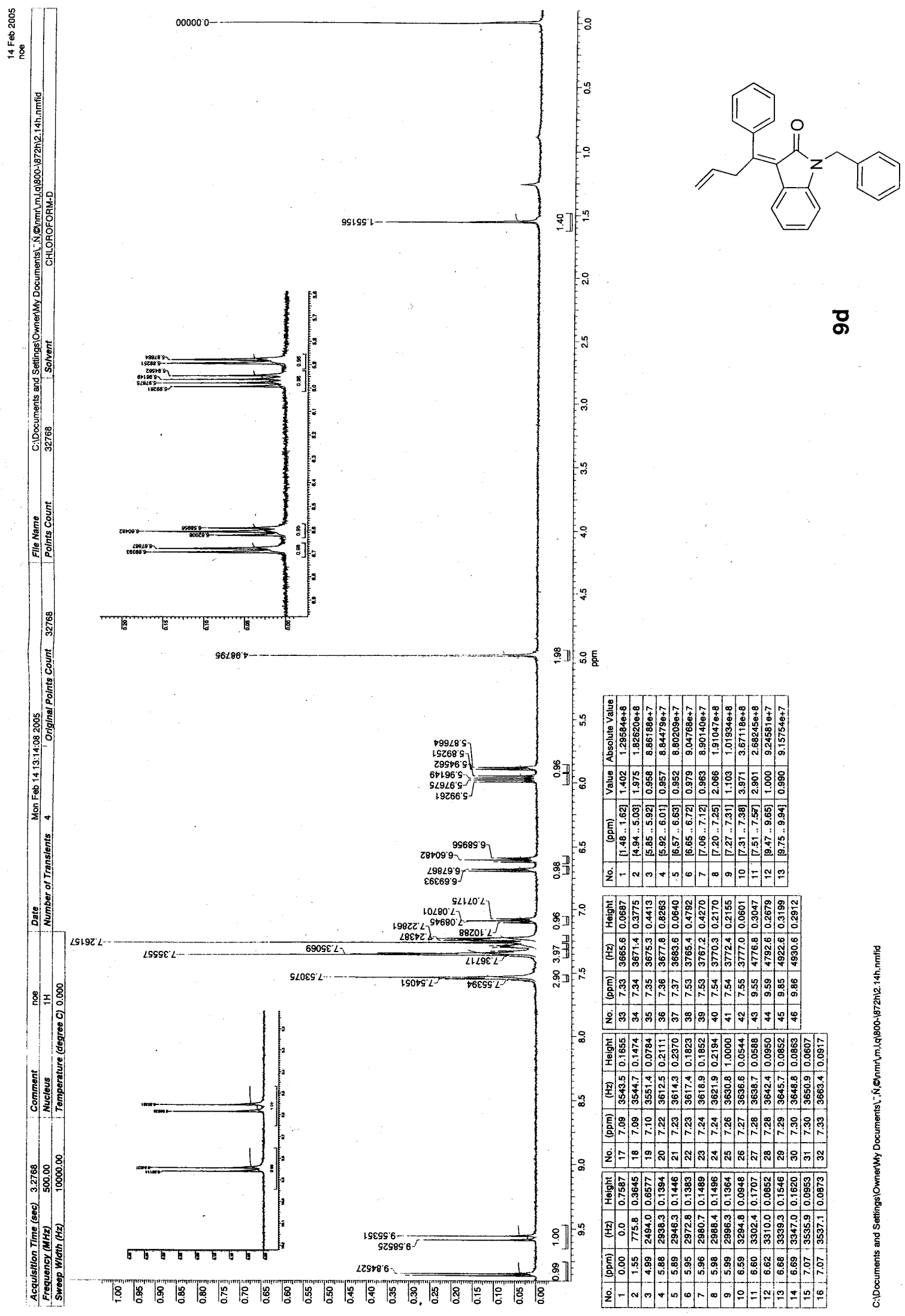




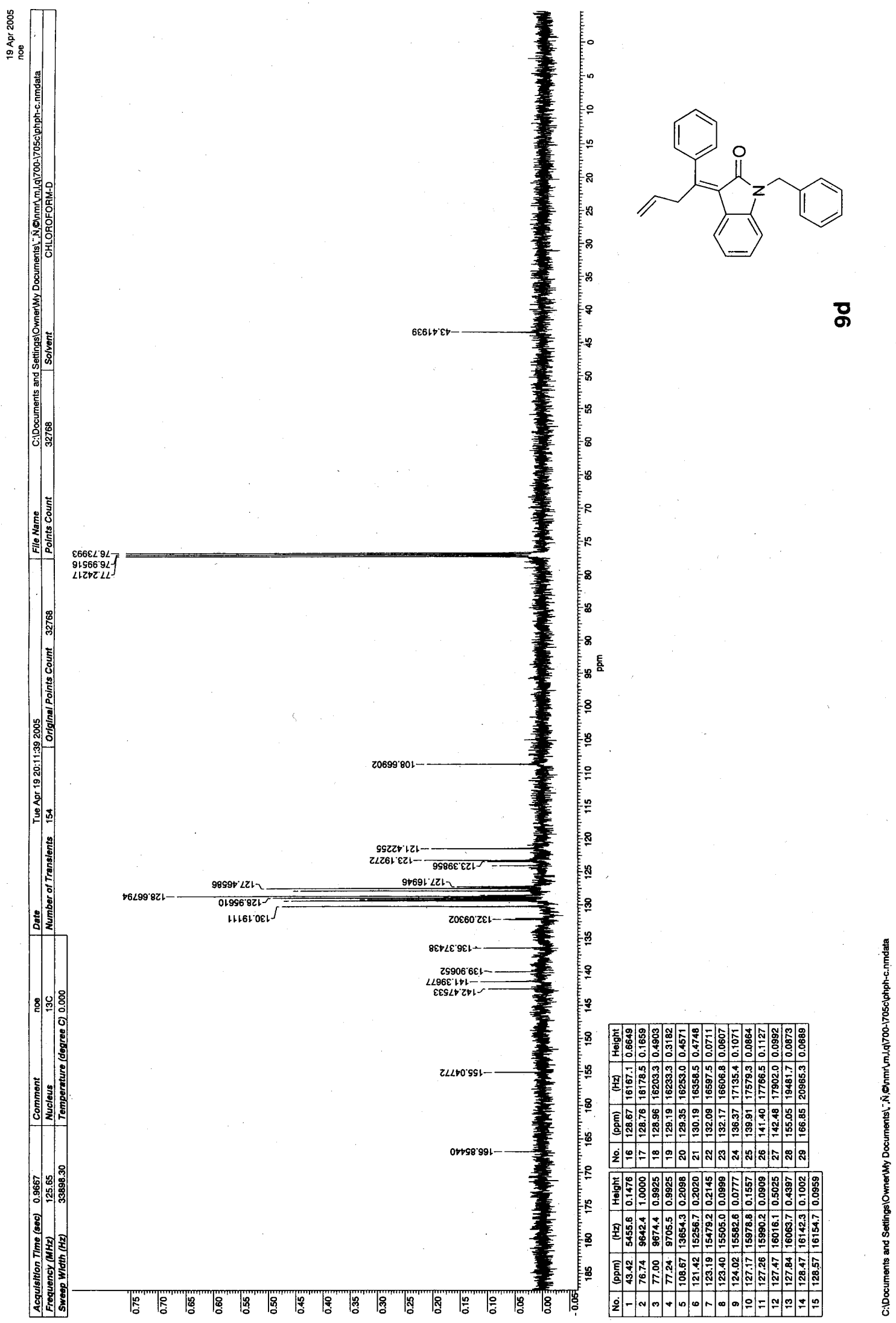

